\title{
Chemical Enhancement of Footwear Impressions in Urine on Fabric
}

\author{
Kevin J. Farrugia ${ }^{a}$, Helen Bandey ${ }^{b}$, Steve Bleay ${ }^{b}$, Niamh NicDaéid ${ }^{{ }^{a *}}$ \\ ${ }^{a}$ Centre for Forensic Science, WestCHEM, Department of Pure and Applied Chemistry, \\ University of Strathclyde, Glasgow, G1 1XW, UK \\ ${ }^{\mathrm{b}}$ Centre for Applied Science and Technology (formerly HOSDB), Woodcock Hill, \\ Sandridge, St. Albans, AL4 9HQ, UK
}

\section{${ }^{1}$ PRESENT ADDRESS}

School of Contemporary Sciences, Division of Forensic and Bio Sciences, University of Abertay, Bell Street, Dundee, DD1 1HG, UK

\section{* CORRESPONDING AUTHOR}

Niamh Nic Daéid

Centre for Forensic Science, WestCHEM, Department of Pure and Applied Chemistry, University of Strathclyde, Glasgow, G1 1XW, UK

n.nicdaeid@strath.ac.uk 


\begin{abstract}
A range of chemical techniques were utilised for the enhancement of footwear impressions deposited on a variety of fabric types of different colours with urine as a contaminant. A semi-automated stamping device was used to deliver test impressions at a set force to minimise the variability between impressions; multiple impressions were produced and enhanced by each reagent to determine the repeatability of the enhancement. Urine samples from different donors were analysed using a spectrofluorophotometer revealing differences between individuals. Results indicated that the enhancement of footwear impressions in urine was possible using amino acid staining techniques whereas protein stains failed to achieve successful enhancement.
\end{abstract}

Keywords: footwear impressions, urine, fabric, enhancement, ninhydrin, DFO, DMAC, 1,2indanedione 


\section{INTRODUCTION}

Urine consists of urea, uric acid, creatine, creatinine, ammonia, chlorine and Tamm-Horsfall glycoprotein amongst other compounds [1-3]. The identification of urine has been based on the detection of inorganic anions such as phosphate and sulphate, as well as organic compounds such as urea, ammonia and creatinine [1]. Most body fluids tend to fluoresce under UV light, however, the fluorescence of urine tends to be much weaker as it is more dilute than other body fluids [3]. Fluorescence occurs when a fluorophore absorbs energy and emits light at a longer wavelength and lower energy. Different compounds present in body fluids, such as nucleic acids, proteins and lipids, metabolite breakdown products in urine, heme in blood and dried semen, have the ability to exhibit fluorescence [2]. Body fluids have characteristic emission spectra which can be used to distinguish them and some compounds are present in more than one body fluid.

Fingerprint reagents that target amino acids, such as ninhydrin and its analogues, could also potentially detect amino acids present in urine. Ninhydrin is a non-specific amino acid reagent well known for the development of latent fingerprints [4-6]. The reaction of ninhydrin results in an intermediate colour change, varying from orange to purple depending on the fingerprint's origin and development conditions $[7,8]$. The final product is a purplecoloured compound called 'Ruhemanns's Purple'. The ninhydrin analogues 1,8-diazafluoren9-one (DFO) and 1,2-indanedione (1,2-IND) are known as dual fingerprint reagents as they offer colorimetric and fluorescent enhancement. Recent research has also introduced new non-ozone depleting solvents, HFE-7100 and HFE-71DE, for the chemical formulations of ninhydrin and its analogues $[9,10]$.

4-dimethlyaminocinnamaldehyde (DMAC) reacts with urea and amino acids to give a magenta coloured product offering the advantage of yellow-green fluorescence using an excitation filter for the wavelength range 400-519nm [11, 12]. Figure 1 shows the reaction between DMAC and urea. During the development of the DMAC process, Sasson and Almog [13] reported that DMAC was superior to ninhydrin on fresh latent fingerprints (up to 72 hours old). Several successful formulations and applications (dipping, spraying, contacttransfer) for DMAC have been proposed [12, 14, 15]. Trials by the Centre for Applied Science and Technology (previously the Home Office Scientific Development Branch, HOSDB) [12] demonstrated that methanol could be replaced with ethanol as a safer substitute 
without any detriment to the process. Brennan et al. $[16,17]$ reported the use of DMAC as a fuming agent with potential success for sequential treatment before the DFO-ninhydrinphysical developer sequence. Ramotowski [18] and Flynn [15] reported the use of DMAC soaked papers put in contact with latent impressions as a means of enhancement where the use of a steaming iron can speed up the process. Recent studies at CAST [12] have also revealed that the contact transfer technique does not appear to react primarily with urea but with the amino acid component of fingerprints. This is in contrast to the solution-dipping DMAC mechanism $[13,16,17]$.

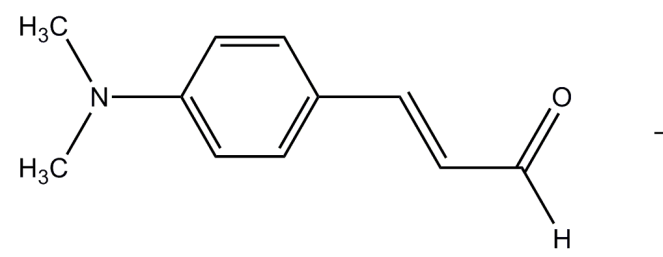

DMAC<smiles>NC(=O)[OH2+]</smiles>

urea<smiles>CN(C)c1ccc(/C=C/C=N/C(N)=O)cc1</smiles>

Figure 1 - The reaction between DMAC and urea

To date no studies have been reported which discuss the possibility of enhancement of footwear impressions where urine is a contaminant. This study comprehensively assesses the suitability of protein stains and four amino acid stains for the enhancement of repetitive footwear impressions in urine as a diminishing series prepared under the exact same conditions and across a variety of fabric types. 


\section{MATERIALS AND METHODS}

\section{Excitation and Emission Spectra of Urine}

Excitation and emission spectra were collected from liquid urine samples from three volunteers and from urine stains on different fabrics using a Shimadzu RF5301 spectrofluorophotometer. A number of different excitation and emission wavelengths were utilised.

\section{Deposition of footwear impressions in urine}

The objective of this work was to compare the ability of various chemical reagents to enhance footwear marks in urine and deposited on various fabrics. The work addresses the potential for the various chemical reagents to facilitate visualisation of the mark under laboratory conditions rather than mimic operational conditions at this stage.

Human urine $(25 \mathrm{~mL})$, obtained with ethical consent of the donors, was poured over two Kimberley ${ }^{\circledR}$ double ply tissues in a tray measuring $0.33 \mathrm{~m} \times 0.23 \mathrm{~m} \times 0.06 \mathrm{~m}$. A stamping device, specifically built to control the variation in pressure during the preparation of test footwear impressions, was used to deliver the footwear impressions onto the fabrics. Controlling the force used to create the footwear impressions is an important requirement for this research in order to compare the enhancement techniques under investigation on a like for like basis and to determine the best technique to apply in a given situation. If the pressure is not controlled, robust comparisons cannot be made. The aim is to determine the best enhancement technique which will allow laboratories to identify which technique suits best for their substrate. In order to do so the force applied to create the sample must be controlled and the evaluation carried out in a systematic fashion. A similar approach has been accepted for the preparation of footwear impressions in blood on fabric [19-21].

The tray containing tissue-soaked urine was put in contact with the sole of the footwear attached to the rig using a stepping motion and the footwear then released onto the fabric. Six repetitions were carried out for each technique and fabric utilised in the study. In each case the test mark was prepared and allowed to age for seven days. A sensitivity test of the techniques using a diminishing series was carried out on the best performing fabric and enhancement reagents. Ageing and sequential treatment studies were also undertaken. 


\section{Chemical Formulations}

Preliminary results for the enhancement of footwear impressions in urine on fabric was undertaken using the protein stains acid black 1 (AB1), acid violet 17 (AV17) and acid yellow 7 (AY7). A full list of chemical reagents and fabrics utilised in the study are presented in tables 1 and 2. Techniques such as the Jaffe test were omitted from the study due to the dangerous nature of the technique. All chemical reagents were prepared as recommended by CAST $[7,12,22]$.

Table 1 - List of chemical reagents

\begin{tabular}{|c|c|c|}
\hline Chemical Name & Alternative Chemical Name & Chemical Supplier \\
\hline Acid Black 1 & Amido Black 10B (C.I. 20470) & BVDA \\
\hline Acid Violet 17 & Coomassie Violet R200 (C.I. 42650) & BVDA \\
\hline Acid Yellow 7 & Brilliant Sulfoflavine (C.I. 56205) & BVDA \\
\hline Ninhydrin & 2,2-Dihydroxy-1,3-indanedione & Sigma Aldrich \\
\hline DFO & 1,8-Diazafluorenone-9-one & BVDA \\
\hline 1,2-IND & 1,2-indanedione & BVDA \\
\hline DMAC & 4-dimethly-aminocinnam-aldehyde & 3 M Novec \\
\hline HFE-7100 & Nonafluorobutyl methyl ether & 3 Novec \\
\hline HFE-71DE & Trans-1,2-dichloroethylene & \\
\hline
\end{tabular}

\section{Fluorescence}

A Mason Vactron Quaser 40 was utilised for fluorescence observations. An initial fluorescence examination of the urine impressions on fabric was carried out prior to any chemical enhancement. A wavelength range of 400-700nm was used as recommended for the visualisation of body fluids [23]. The appropriate excitation and viewing wavelengths/filters which were utilised for observation of fluorescent chemical reagents are presented in table 3. The wavelengths represented in this table 3 show the $1 \%$ cut-on and cut-off points [24]. Computer monitor and colour calibration was achieved and fluorescence photography performed as described previously in the literature [20]. 
Table 2 - List of fabrics

\begin{tabular}{|c|c|}
\hline Fabric & Supplier \\
\hline $\begin{array}{c}\text { White Cotton [CD13] } \\
\text { Plain weave; } 19 \text { warp threads/cm; } 10 \text { weft } \\
\text { threads/cm }\end{array}$ & WBL Whaleys Bradford Ltd. \\
\hline $\begin{array}{c}\text { Black Cotton [CD13D] } \\
\text { Plain weave; } 19 \text { warp threads/cm; } 10 \text { weft } \\
\text { threads/cm }\end{array}$ & WBL Whaleys Bradford Ltd. \\
\hline $\begin{array}{c}\text { Patterned Cotton [SF2360/B] } \\
\text { Twill weave; } 19 \text { warp threads/cm; } 19 \text { weft } \\
\text { threads/cm }\end{array}$ & WBL Whaleys Bradford Ltd. \\
\hline White Polyester Taffeta [SF25] & WBL Whaleys Bradford Ltd. \\
\hline Black Polyester Taffeta [SF25A] & WBL Whaleys Bradford Ltd. \\
\hline White Nylon (82\%) / Lycra (18\%) [SF28] & WBL Whaleys Bradford Ltd. \\
\hline $\begin{array}{c}\text { Black Nylon (82\%) / Lycra (18\%) [SF27] } \\
\text { Blue Denim [Rialto Indigo] } \\
\text { Twill weave; 25 warp threads/cm; } 19 \text { weft } \\
\text { threads/cm }\end{array}$ & WBL Whaleys Bradford Ltd. \\
\hline Brown Bovine Leather & Mandors, Glasgow, UK \\
\hline
\end{tabular}

Table 3 - Excitation wavelength and viewing filters for a Mason Vactron Quaser 40

\begin{tabular}{|c|c|c|c|c|}
\hline $\begin{array}{c}\text { Chemical } \\
\text { Name }\end{array}$ & $\begin{array}{c}\text { Excitation } \\
\text { Wavelength/nm }\end{array}$ & $\begin{array}{c}\text { Excitation } \\
\text { Filters }\end{array}$ & $\begin{array}{c}\text { Viewing } \\
\text { Filter/nm }\end{array}$ & $\begin{array}{c}\text { Viewing } \\
\text { Filter }\end{array}$ \\
\hline AY7 & $385-509$ & Blue & 510 & Yellow/Orange \\
\hline DFO & $473-548$ & Green & 549 & Orange \\
\hline 1,2-IND & $473-548$ & Green & 549 & Orange \\
\hline DMAC & $473-548$ & Green & 549 & Orange \\
\hline
\end{tabular}

\section{Protein Stains}

Fixing solution: 5-sulfosalicylic acid (Acros, 23g) was dissolved and stirred in distilled water, (1L). The fabrics were immersed for a minimum period of 5 minutes to fix the impressions present. 
Staining solution: The required protein stain, $(1 \mathrm{~g})$, was stirred for at least 30 minutes in a solution of acetic acid (Sigma, 50mL), ethanol (Sigma, 250mL) and distilled water $(700 \mathrm{~mL})$. This was used to stain the impression by immersion for a minimum period of 3 minutes. The protein stains used were acid black 1 (AB1), acid violet 17 (AV17) and acid yellow 7 (AY7).

Destaining solution: A solution of acetic acid (Sigma, 50mL), ethanol (Sigma, 250mL) and distilled water $(700 \mathrm{~mL})$ was used to wash the excess dye from the background.

\section{Ninhydrin}

Ninhydrin Concentrated Solution: Ninhydrin (Sigma, 25g), was dissolved in absolute ethanol (Sigma, 225mL). Ethyl acetate (Sigma, 10mL) followed by acetic acid (Sigma, $25 \mathrm{~mL}$ ) was added to the slurry and stirred until a clear yellow solution was produced.

Ninhydrin Working Solution: HFE 7100 (3M Novec, 1L) was added to the ninhydrin concentrated solution $(52 \mathrm{~mL})$ with stirring.

Treatment of articles with Ninhydrin: The fabric was immersed in the working solution for a maximum of five seconds. The excess solution was allowed to drain back into the tray. The fabric was allowed to dry in air and then heated using a conventional hair dryer [7].

\section{1,8-Diazafluoren-9-one (DFO)}

DFO Working Solution: DFO (BVDA, 0.25g) was dissolved in methanol (Sigma, 30mL) using a magnetic stirrer to produce a slurry. Acetic acid (Sigma, 20mL) was added and stirred until a clear, yellow solution was produced. HFE71DE (3M Novec, 275mL) and HFE7100 (3M Novec, $725 \mathrm{~mL}$ ) were added sequentially with continued stirring.

Treatment of articles with DFO: The fabric was immersed in the working solution for a maximum of five seconds. The excess solution was allowed to drain back in the tray and the fabric was allowed to dry completely before being heated in an oven at $100^{\circ} \mathrm{C}$ for 20 minutes without humidification. Fluorescence examination was carried out using a green excitation source (band pass filter $473-548 \mathrm{~nm}$ at $1 \%$ cut-on and cut-off points respectively) and viewed with a long pass $549 \mathrm{~nm}$ filter ( $1 \%$ cut-on point). 


\section{1,2-IND}

1,2-Indanedione Working Solution: 1,2-indanedione (BVDA, 0.25g) was weighed and dissolved in a solution of ethyl acetate (Sigma, 90mL), acetic acid (Sigma, $10 \mathrm{~mL}$ ) and $\mathrm{ZnCl}_{2}$ (Sigma, 0.5mL) with stirring. HFE-7100 (3M Novec, 1L) was added to the mixture and stirred.

$\mathrm{ZnCl}_{2}$ Stock Solution: Anhydrous zinc chloride (Sigma, 0.2g) was dissolved in absolute ethanol (Sigma, 5mL).

Treatment of articles with 1,2-Indanedione: The fabric was immersed in the working solution for a maximum of five seconds. The excess solution was allowed to drain back in the tray and the fabric was allowed to dry completely before heated in an oven at $100^{\circ} \mathrm{C}$ for 10 minutes without humidification. Fluorescence examination was carried out using a green excitation source (band pass filter $473-548 \mathrm{~nm}$ at $1 \%$ cut-on and cut-off points respectively) and viewed with a long pass $549 \mathrm{~nm}$ filter ( $1 \%$ cut-on point).

\section{DMAC}

Pre-impregnated DMAC sheets: DMAC (Acros, 0.25g) was weighed and dissolved in ethanol (Sigma, 100mL) with stirring. The solution was poured into a dipping tray and white A4 sheets of copier paper were soaked in the solution. The sheets were left to dry in a fume hood, sealed in a Ziploc bag and stored in a refrigerator until needed.

Treatment of articles: Articles to be treated were placed between two sheets of paper preimpregnated with DMAC such that a pre-impregnated DMAC sheet was placed between each article and then finally wrapped in two sheets of aluminium foil. The layers were either heated for about 30 seconds via an iron or left in a press overnight. DMAC enhanced impressions emit light in the green, yellow and orange region of the spectrum with a maximum at approximately 530nm. The impressions were viewed using blue (385-509nm), blue/green (468nm) and green (473-548nm) Quaser bands. Best results were obtained using a green excitation source (band pass filter 473-548nm at 1\% cut-on and cut-off points respectively) and viewed with a long pass $549 \mathrm{~nm}$ filter (1\% cut-on point). 


\section{Sensitivity of Techniques and Ageing of Impressions}

The best performing techniques and fabrics were examined further by creating a diminishing series of footwear impressions where impressions were produced one after the other without re-loading the footwear sole with urine in between impressions. Sensitivity tests were performed through a diminishing series rather than using diluted urine. The possibility of diluting urine samples and prepare footwear impressions in urine on fabric for sensitivity tests was considered, however, it was deemed as less realistic than a diminishing series. Furthermore, in 2005, Sears et al. [25] reported that dilution with water might not be the most effective measure for sensitivity in enhancement experiments. The diminishing series was prepared up to the fifth impression and allowed to age for one week. Each impression was then cut in half and chemically treated to facilitate the following comparisons: NIN-DFO, DFO-DMAC and NIN-DMAC. Samples were also prepared as previously described and aged for two months prior to enhancement. 


\section{RESULTS AND DISCUSSION}

\section{Excitation and Emission Spectra of Urine}

The main fluorophores in human urine that fluoresce under UV light are tryptophan and its metabolites, indoxyl sulphate and 5-hydroxyindole-3-acetate [26-28]. Undiluted human urine weakly fluoresces under short wave UV excitation (250-300nm) [26] and this fluorescence can be reduced by high concentrations of indoxyl sulphate 'that contribute to the concentration quenching of fluorophores by ammonium' [28]. This can explain the different excitation and emission spectra of urine from different donors in figures 2-5. The emission spectrum $400-700 \mathrm{~nm}$ with an excitation at $380 \mathrm{~nm}$ in figure 2 is consistent between the three donors. This emission spectrum shows that the maximum emission is approximately $470 \mathrm{~nm}$, suggesting that a strong fluorescence of urine would be observed by using a violet/blue excitation source (band pass filter $350-469 \mathrm{~nm}$ at $1 \%$ cut-on and cut-off points respectively) and viewed with a long pass $476 \mathrm{~nm}$ filter (1\% cut-on point). This observation differs slightly to previous research at CAST where the strongest emission was observed around 440nm [29]. This difference can be attributed to different urine samples having different concentrations of fluorophores. The excitation spectra (figures 3-5) at different wavelengths vary between one donor to another indicating that the concentrations of fluorophores in the urine samples vary between donors. Differences between and within donor samples were expected and research by Rasmussen et al.[30] illustrated the ability to distinguish human urine samples by nuclear magnetic resonance (NMR) based on gender and diet. Measurements of the same excitation and emission spectra on one-week old urine stains from different donors on different fabrics and the appropriate fabric blanks failed to produce distinguishable spectra. This is in contrast to the differences observed in the excitation and emission spectra of liquid urine from different donors.

\section{Preliminary Work}

\section{Urine sample}

Preliminary experiments utilised urine samples (obtained with ethical consent of the donors) from a male, a female and a vegetarian volunteer to prepare footwear impressions on all fabrics used in this study. Such impressions did not yield any comparable differences when enhanced with ninhydrin, DFO, 1,2-indanedione or DMAC and as such samples collected from one individual was utilised for the remainder of the experiments. 


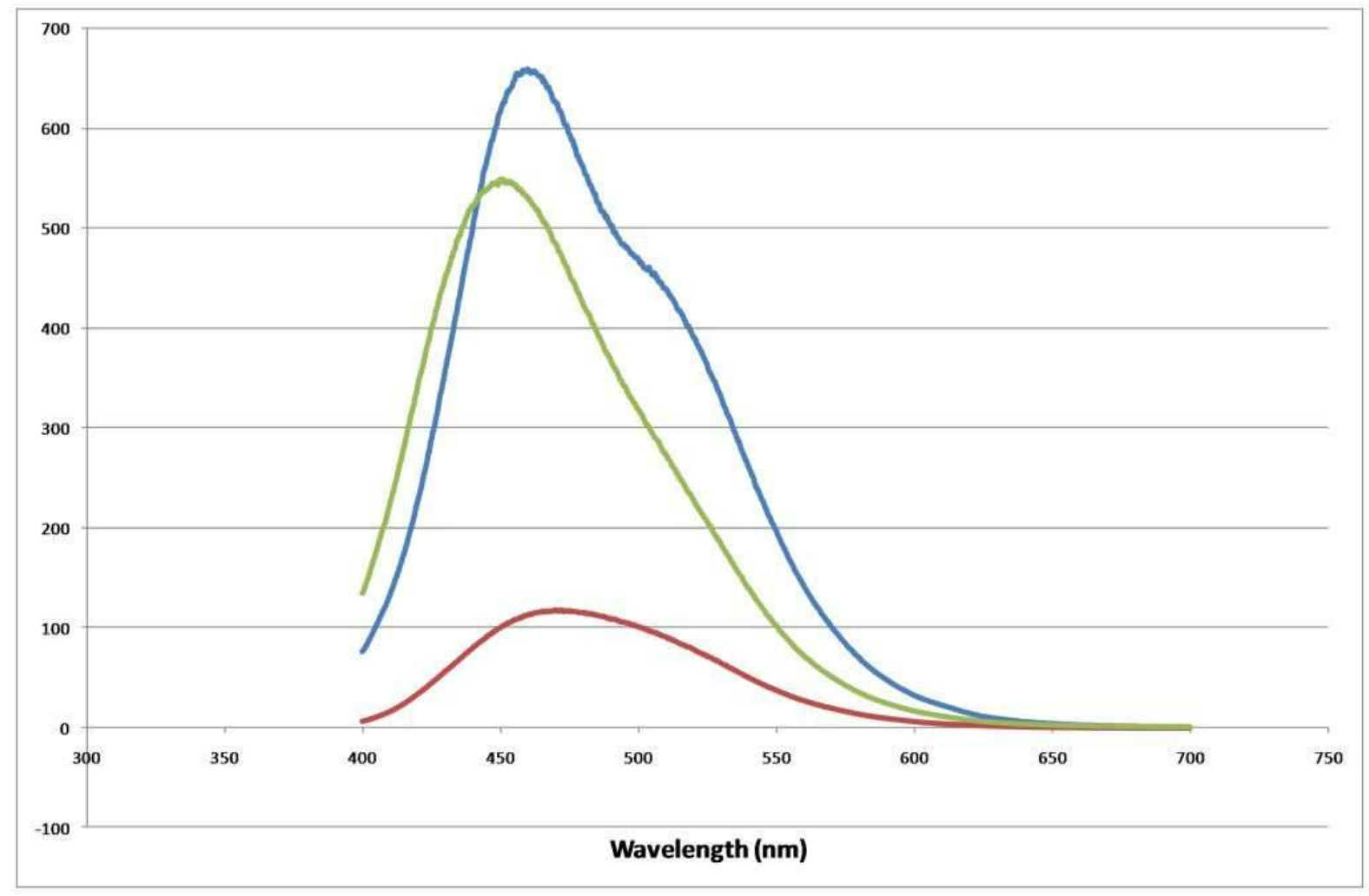

Figure 2 - Emission spectrum $(400-700 \mathrm{~nm})$ of undiluted human urine from three different donors (excitation at 380 nm)

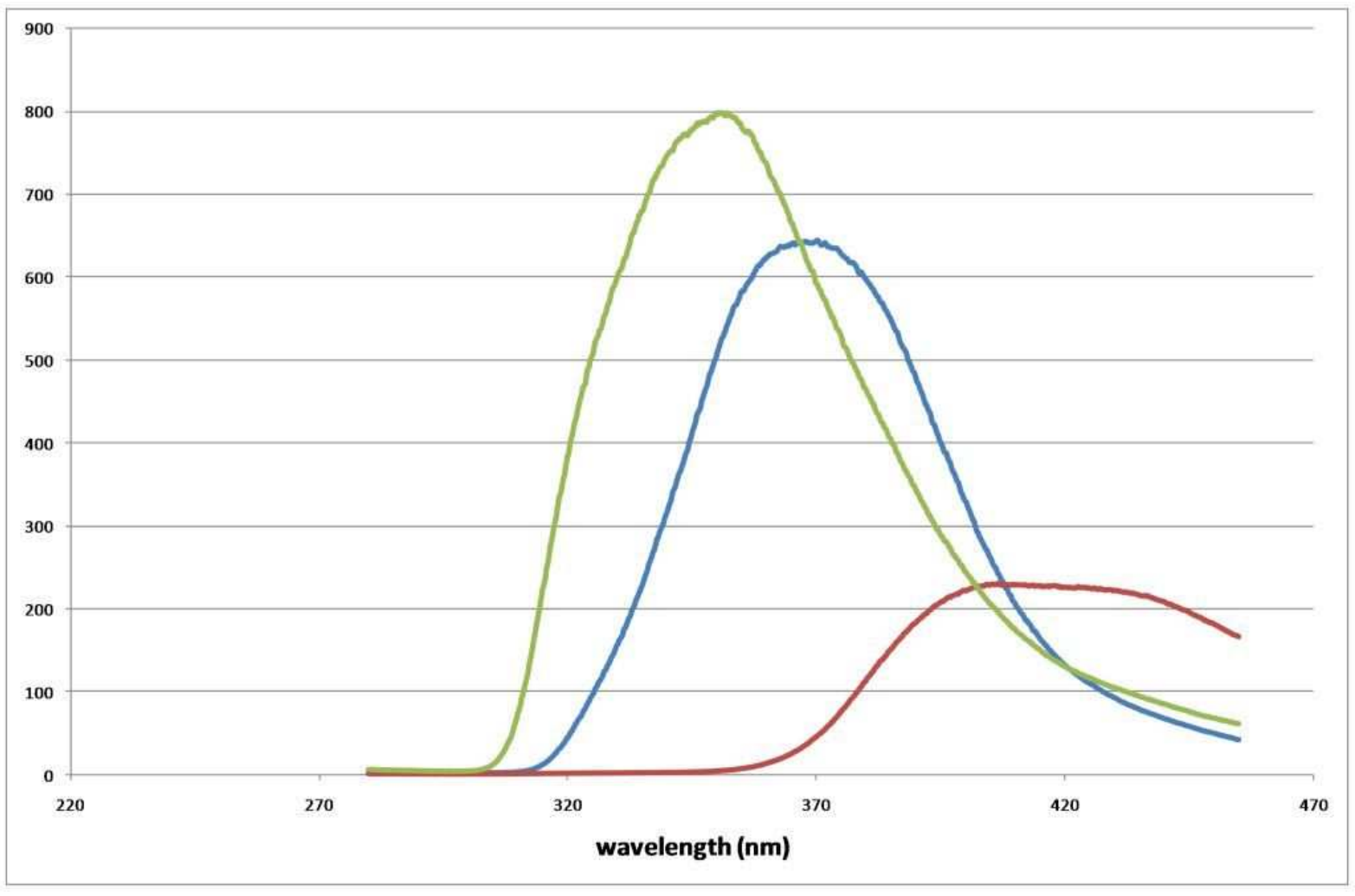

Figure 3 - Excitation spectrum (280-455nm) of undiluted human urine from three different donors (emission at $475 \mathrm{~nm}$ ) 


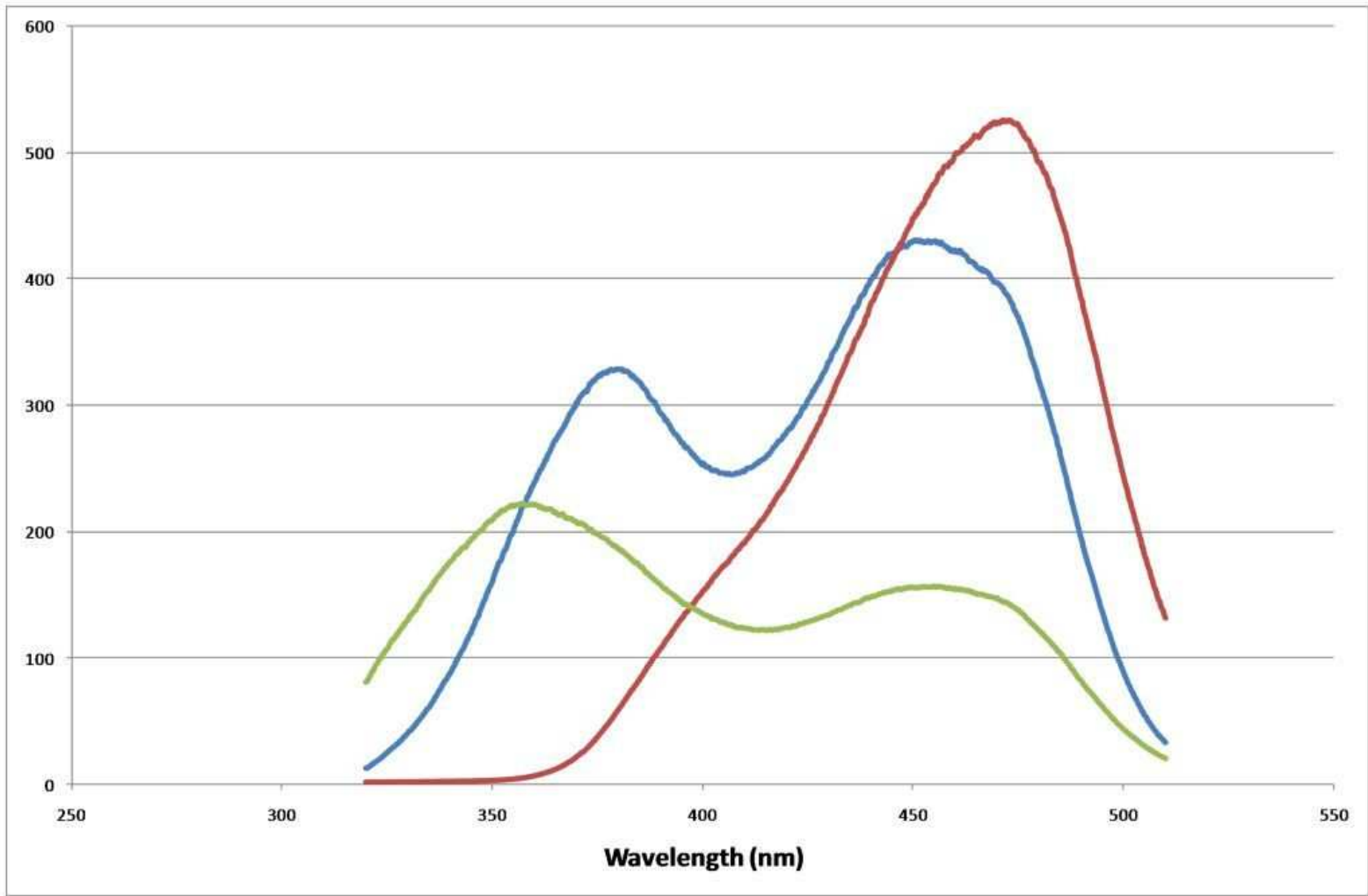

Figure 4 - Excitation spectrum (320-510nm) of undiluted human urine from three different donors (emission at 530nm)

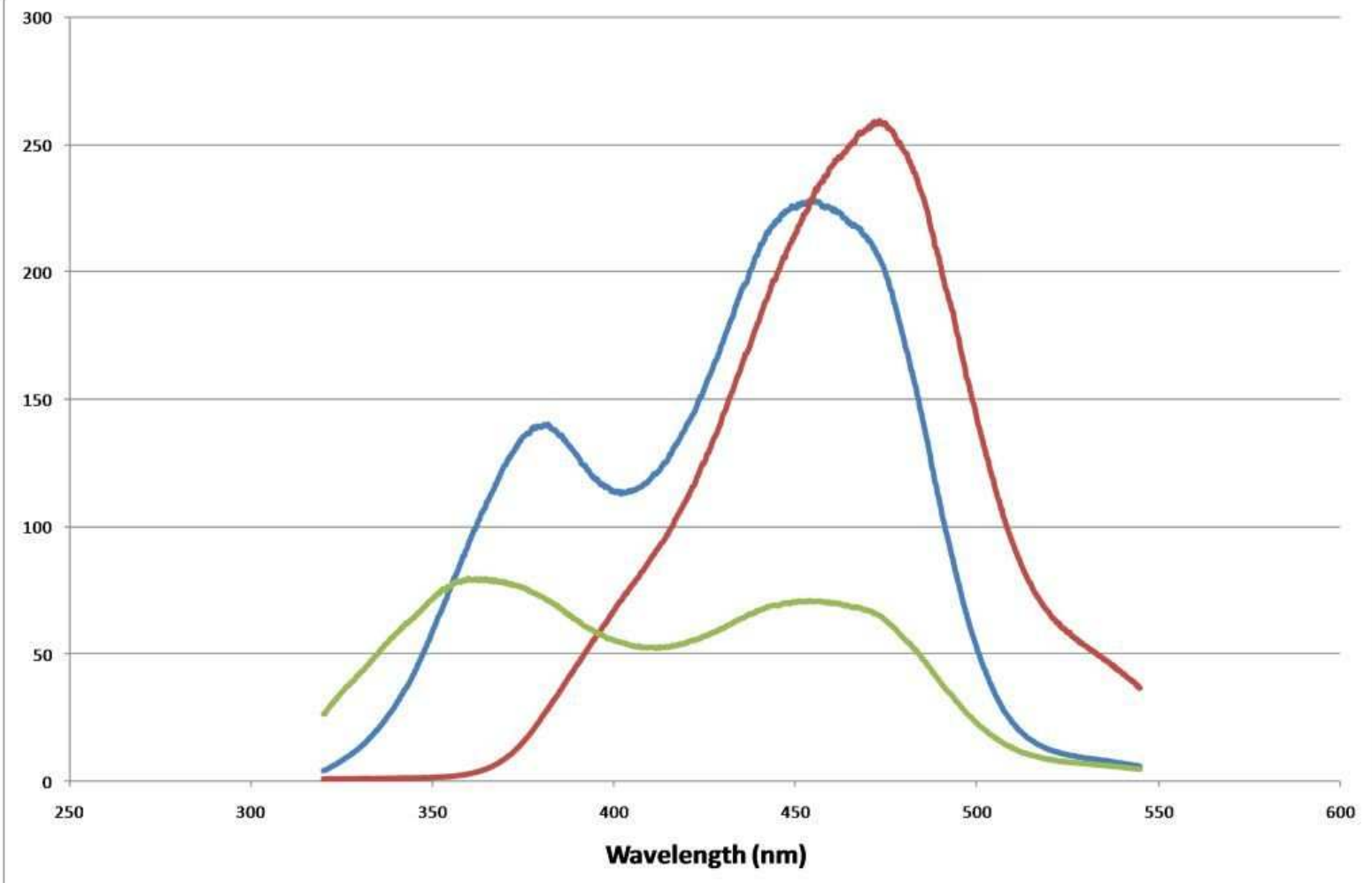

Figure 5 - Excitation spectrum (320-545nm) of undiluted human urine from three different donors (emission at 560nm) 
Footwear impressions in urine on all fabrics used in this study were allowed to age for 1,7 , 14 and 28 days before chemical treatment. The enhanced impressions appeared visually similar after the different ageing periods, although slight diffusion of the impression was observed after one day, indicating that the stain must be dry before chemical processing. As a result, all impressions were allowed to age for 7 days at room temperature for practical reasons.

\section{Enhancement techniques}

\section{Fluorescence}

An initial fluorescence search prior to enhancement using different Quaser bands (Quaser 40, Mason Vactron UK) was carried out using the appropriate excitation and viewing filters [24]. Different excitation filters, including violet/blue (385-469), blue (385-519), green (473-548) and red (503-591), offered good visualisation of the marks as illustrated in figure 6. These marks were not visible under white light and fluorescence provided the advantage of visualisation prior to chemical treatment. Fluorescence did not visualise any marks on black fabrics, denim or leather.

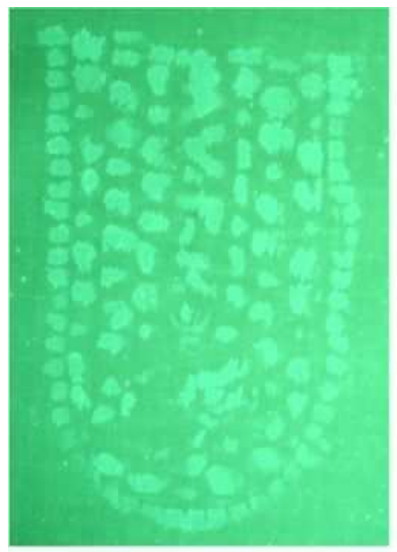

(a)

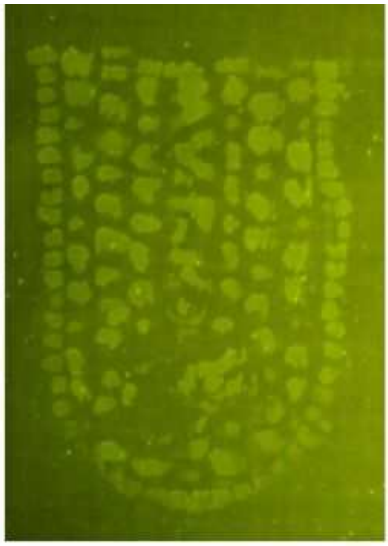

(b)

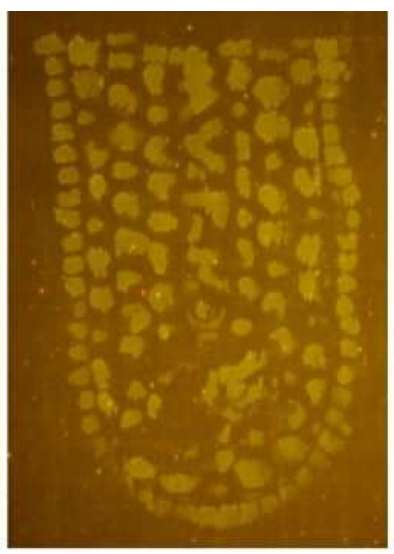

(c)

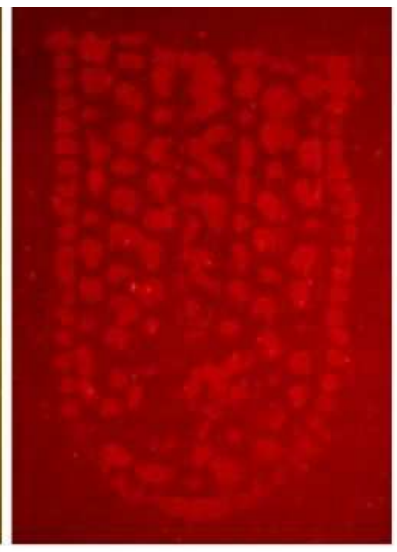

(d)

Figure 6 - Preliminary work on the fluorescence of footwear impressions in urine on white cotton with different Mason Vactron Quaser 40 excitation sources: (a) violet/blue [350-469nm]; (b) blue [385-509nm]; (c) green [473-548nm]; (d) green/yellow [503-591nm] 


\section{Protein Stains}

The protein stains AB1, AV17 and AY7 were initially tested for the enhancement of urine on white cotton and white polyester. AY7 enhancement was also attempted on black cotton and black polyester as enhancement of impressions in blood on dark substrates had previously been successful $[20,25,31]$. No enhancement, either visual or fluorescence, was observed for any fabric, presumably due to the fact that the proteins present in urine were greatly diluted in comparison to the protein levels found in blood.

\section{Ninhydrin}

The use of ninhydrin for the enhancement of urine impressions on light coloured fabric provided excellent results. The purple enhancement colour initially visible after application of heat became progressively darker over time reaching a maximum after about 24 hours. The purple colour was only visible on light coloured fabrics due to poor contrast on all dark coloured fabrics. The initial unenhanced urine impression was visible as soon as it was prepared on the fabric as shown in figure 7(a), but the visibility decreased as the stain dried with the exception of polyester where the impression remained visible for up to a week at least. The urine impressions on polyester were diffused and blurred due to the hydrophobic nature of the fabric which obliterated the fine detail of the footwear impression on this surface. Ninhydrin enhancement on nylon/lycra spread to stain the whole background and quick photography was essential to view the optimal enhancement. The use of a blue excitation filter improved the contrast when background staining occurred and is illustrated in figure 8(c).

Ninhydrin is a versatile technique that can be used for the enhancement of latent fingerprints [7], impressions in blood [32] and now, impressions in urine. Ninhydrin working solutions can be prepared when needed from a ninhydrin stock solution to limit the cost of HFE-7100 and have a shelf life of approximately 12 months. 


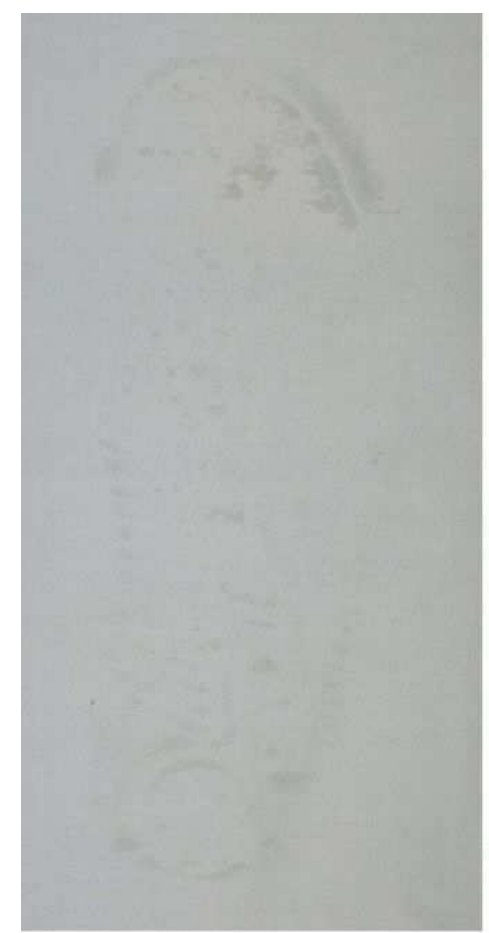

(a)

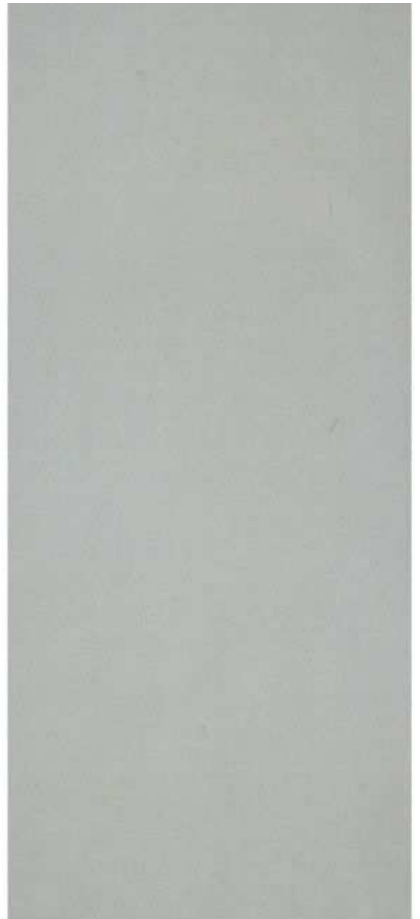

(b)

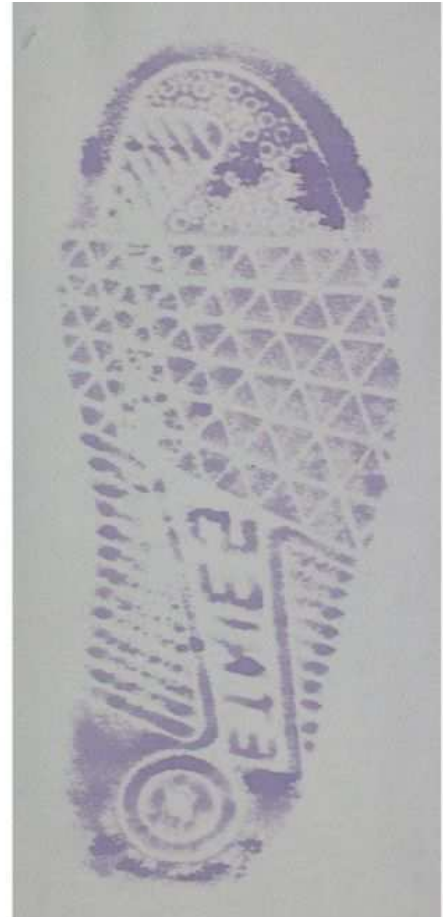

(c)

Figure 7 - Enhancement of a footwear impression in urine on white cotton: (a) fresh urine impression; (b) 1 week old urine impression; (c) ninhydrin enhancement

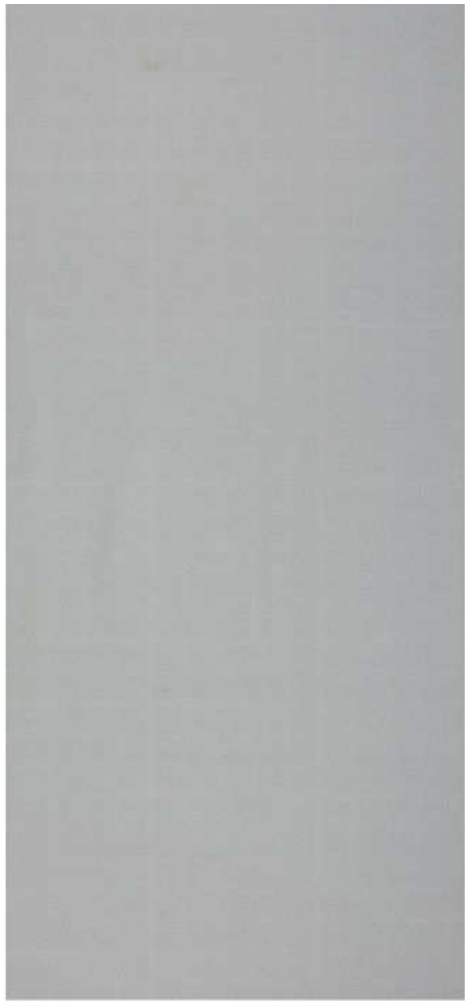

(a)

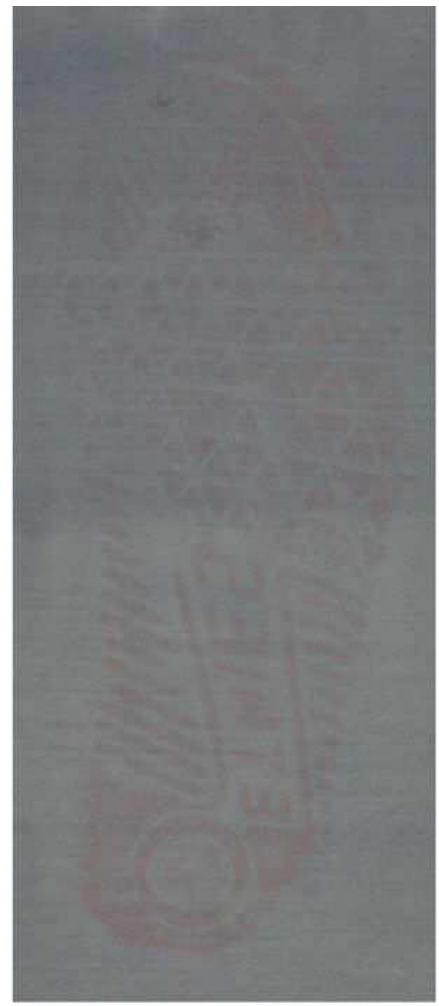

(b)

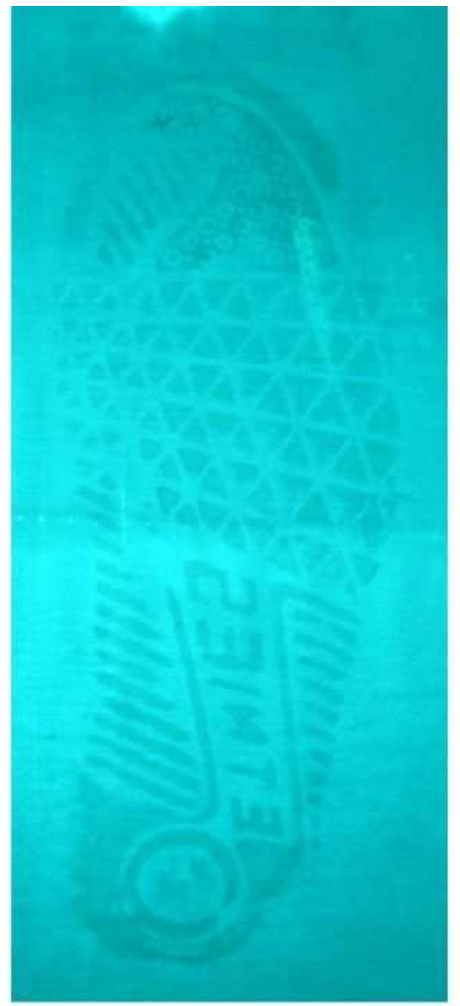

(c)

Figure 8 - Enhancement of a footwear impression in urine on white nylon/lycra (a) 1 week old urine impression; (b) ninhydrin enhancement under white light; (c) ninhydrin enhancement using a Quaser 40 blue excitation source 


\section{1,8-Diazafluoren-9-one (DFO)}

DFO, which will react with traces of amino acids (present in urine) [33, 34] successfully enhanced impressions in urine made on all of the light coloured fabrics. Following oven treatment at $100^{\circ} \mathrm{C}$ for 20 minutes, the footwear impressions yielded a bright magenta colour on light coloured fabrics which was further enhanced using fluorescence. On white cotton, the impression was easily visualised as illustrated in figure 9 without the requirement for fluorescence. This is significantly different from the utilisation of this reagent in conventional fingerprint enhancement where fluorescence is conventionally used and demonstrates a less time consuming application of the technique. However, visualisation of the impressions on patterned cotton demonstrated poor contrast which could be resolved with fluorescence as shown in figure 10. No fluorescence was observed on black fabrics, denim or leather and only diffused enhancement was achieved on polyester.

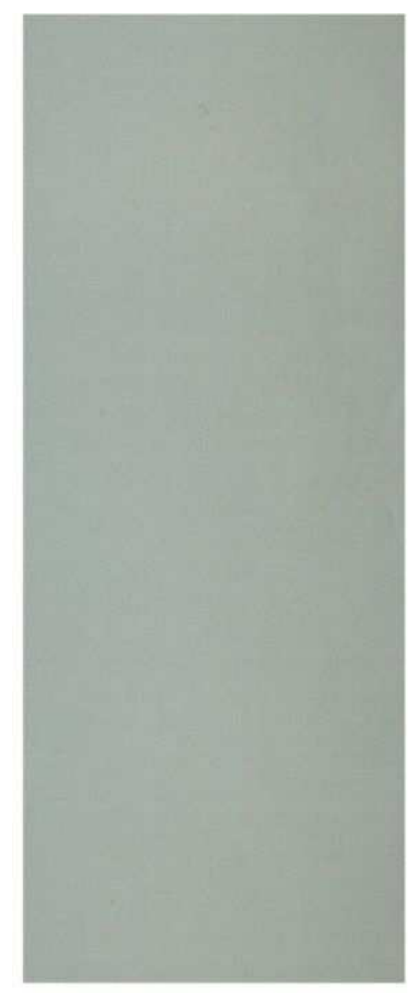

(a)

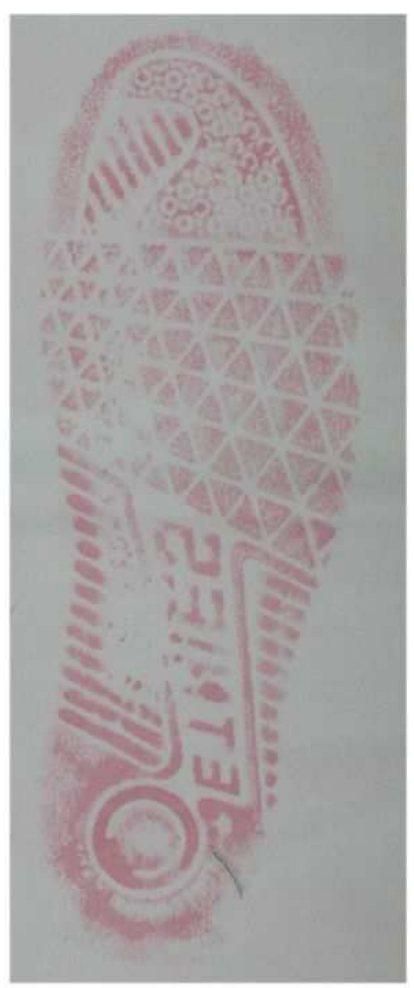

(b)

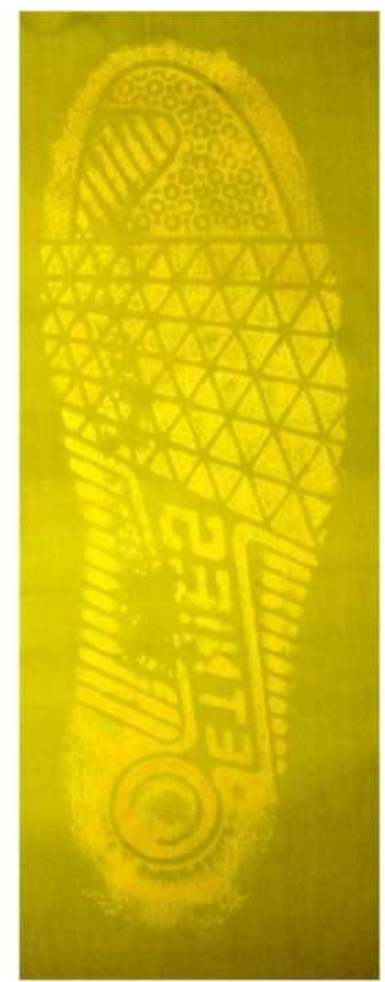

(c)

Figure 9 - Enhancement of a footwear impression in urine on white cotton (a) 1 week old urine impression; (b) DFO enhancement under white light; (c) DFO enhancement using a Quaser 40 green excitation source 


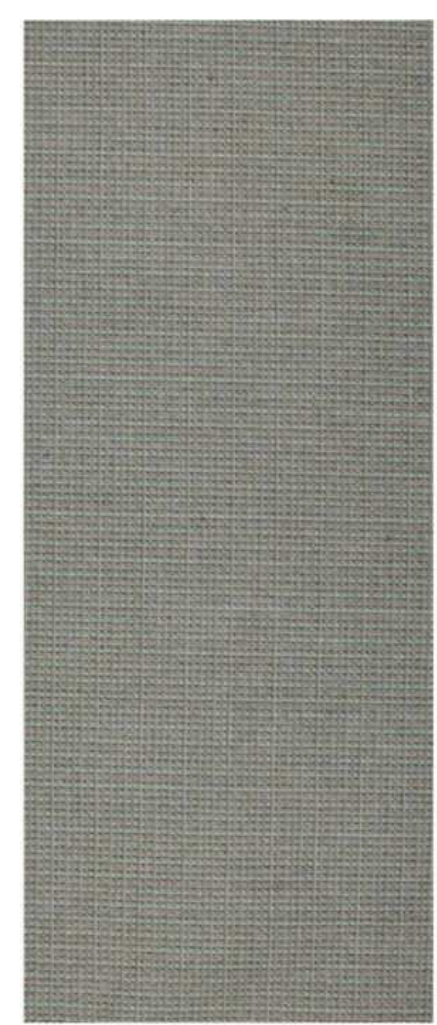

(a)

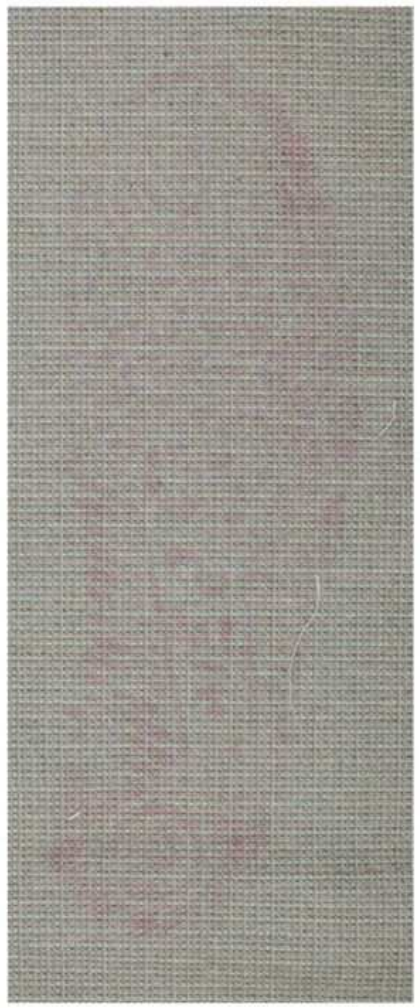

(b)

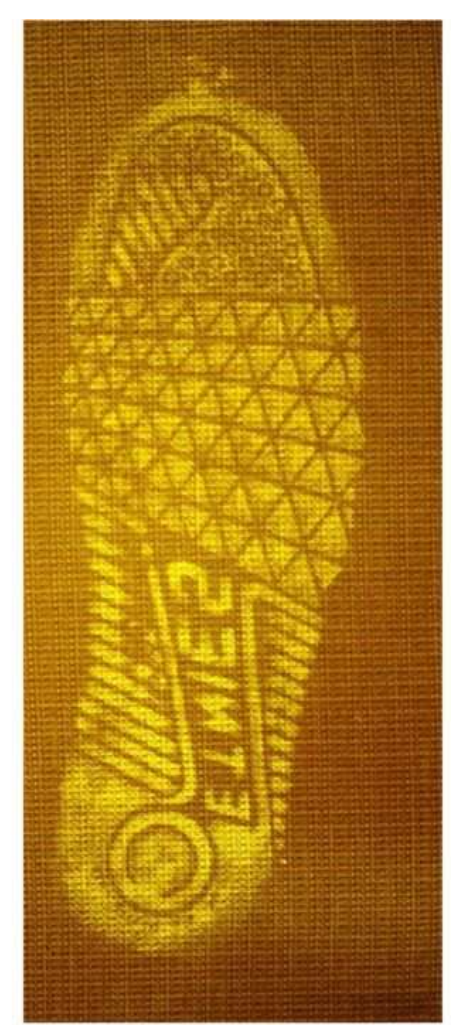

(c)

Figure 10 - Enhancement of a footwear impression in urine on patterned cotton (a) 1 week old urine impression; (b) DFO enhancement under white light; (c) DFO enhancement using a Quaser 40 green excitation source

\section{$D M A C$}

In the contact transfer method, DMAC is believed to react with amino acids rather than urea [12]. DMAC enhancement of impressions in urine was similar to that obtained from DFO. Successful enhancement was achieved again on all of the light coloured fabrics. Visual observation after DMAC enhancement on white cotton was possible and fluorescence examination further enhanced the impression (figure 11). The impressions on patterned cotton could only be observed using fluorescence (figure 12). The enhancement of the impressions prepared on nylon/lycra by DMAC was limited however some enhancement could be observed using fluorescence (figure 13). No visual or fluorescent enhancement was achieved on black fabrics, denim or leather. 


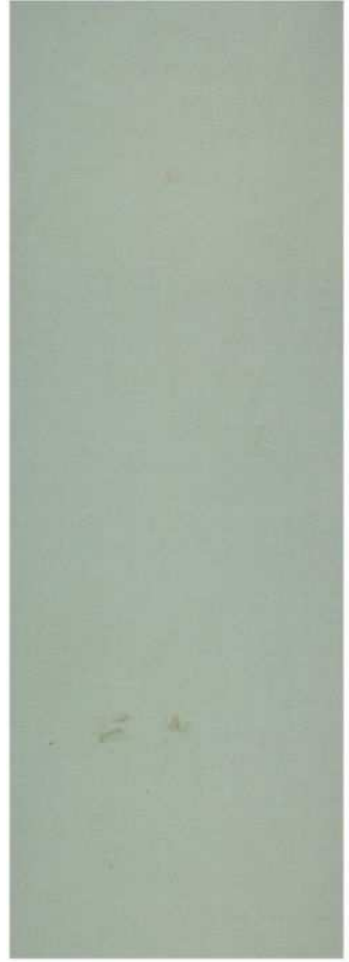

(a)

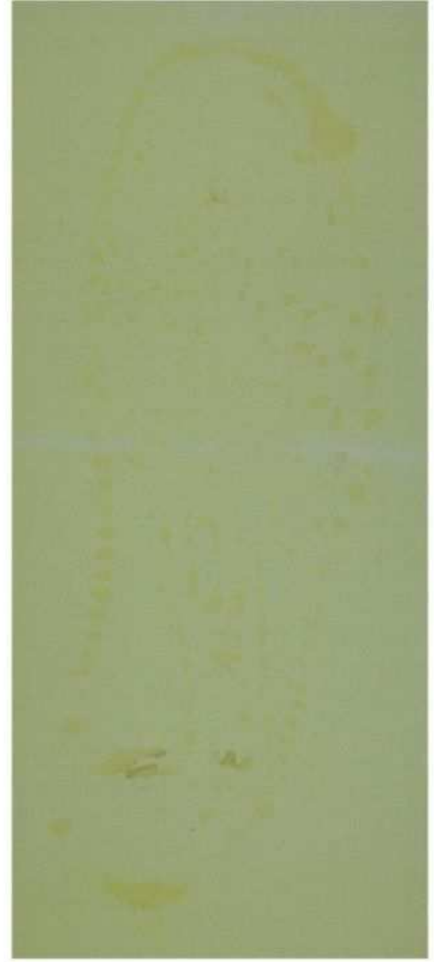

(b)

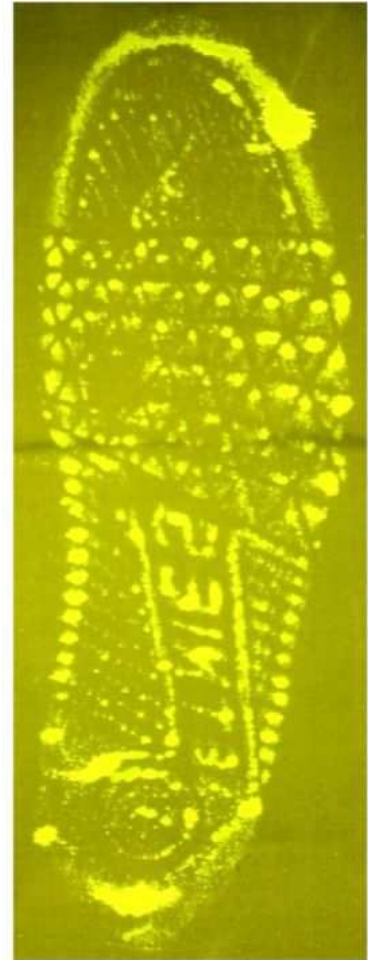

(c)

Figure 11 - Enhancement of a footwear impression in urine on white cotton (a) 1 week old urine impression; (b) DMAC enhancement under white light; (c) DMAC enhancement using a Quaser 40 green excitation source

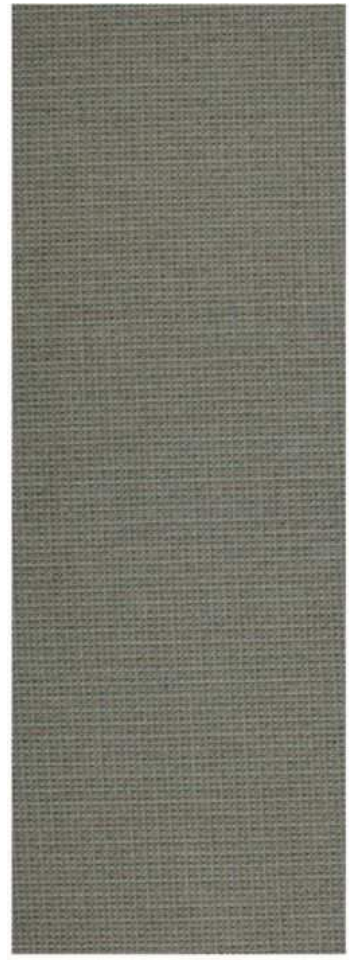

(a)

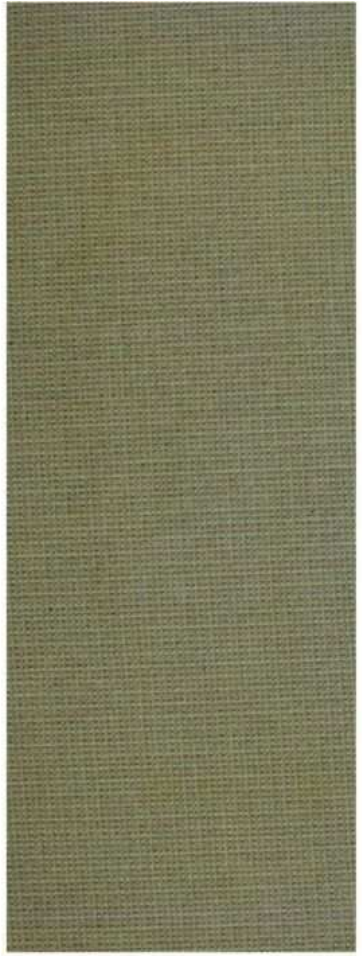

(b)

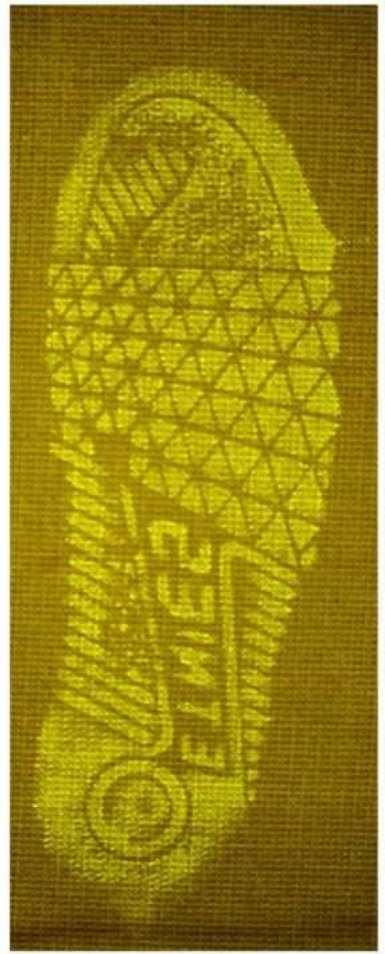

(c)

Figure 12 - Enhancement of a footwear impression in urine on patterned cotton (a) 1 week old urine impression; (b) DMAC enhancement under white light; (c) DMAC enhancement using a Quaser 40 green excitation source 


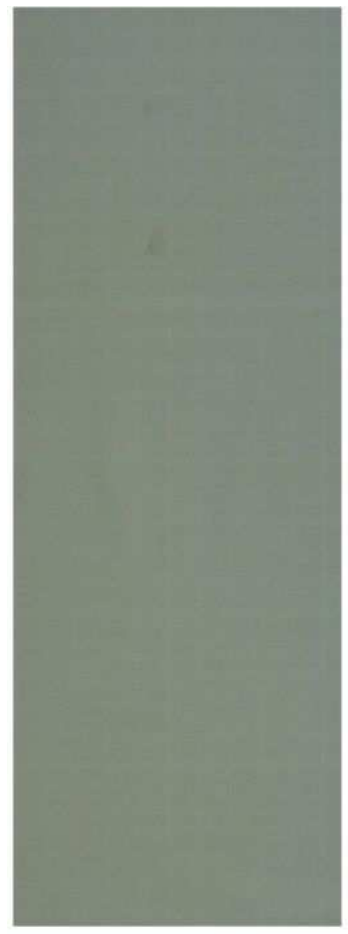

(a)

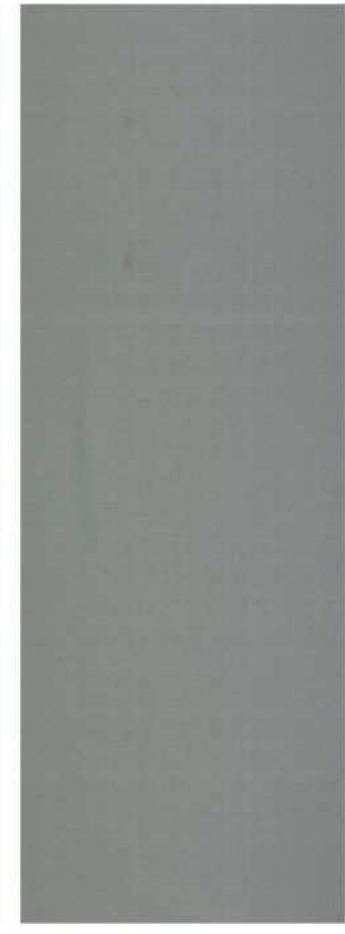

(b)

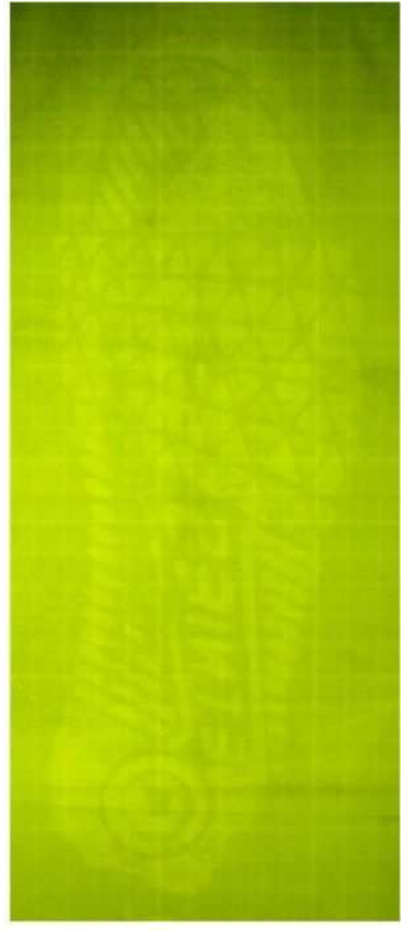

(c)

Figure 13 - Enhancement of a footwear impression in urine on white nylon/lycra (a) 1 week old urine impression; (b) DMAC enhancement under white light; (c) DMAC enhancement using a Quaser 40 green excitation source

\section{$1,2-I N D$}

1,2-IND showed similar enhancement to that produced by DFO, however visual enhancement on light coloured fabric was considerably weaker than DFO while fluorescence enhancement on light coloured fabrics was comparable as shown in figure 14. Similar to DFO and DMAC, no visual or fluorescent enhancement was achieved on black fabrics, denim or leather. The use of lasers at different wavelengths did not improve the fluorescence achieved by the Quaser 40 and the lack of success with DFO, DMAC and 1,2-IND in enhancing marks on black and dark fabrics may possibly be due to interference from the dyes utilised in the manufacturing processes.

The optimum conditions for the application of 1,2-IND and its effectiveness compared to DFO for the enhancement of latent fingerprints on porous surfaces has been well researched [22, 35-43]. It has been reported that the climatic conditions in different countries (and even within) may have an effect on the performance of 1,2-IND and DFO. For example studies in countries such as Israel, USA and Australia demonstrated that 1,2-IND was superior to DFO, whereas the reverse was reported from studies in the UK and Canada [22, 43]. Recent studies 
$[25,36,41]$ confirmed that the addition of zinc salts greatly improves the fluorescence intensity of 1,2-IND products, however DFO was found to marginally outperform 1,2-IND for the enhancement of latent fingerprints on porous surfaces [22]. In this study, similar to other studies in the UK, DFO appeared to be superior to 1,2-IND.

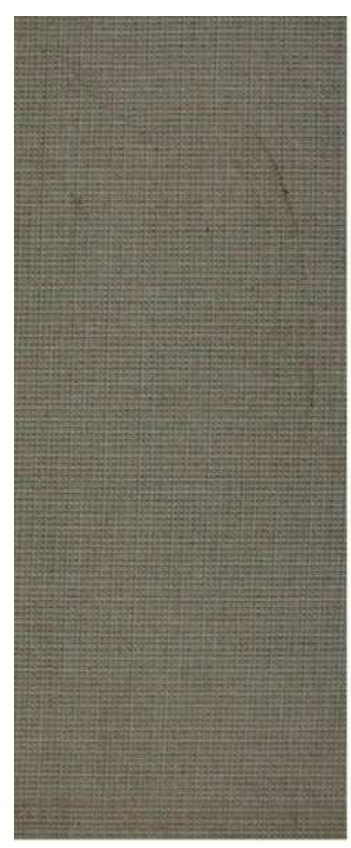

(a)

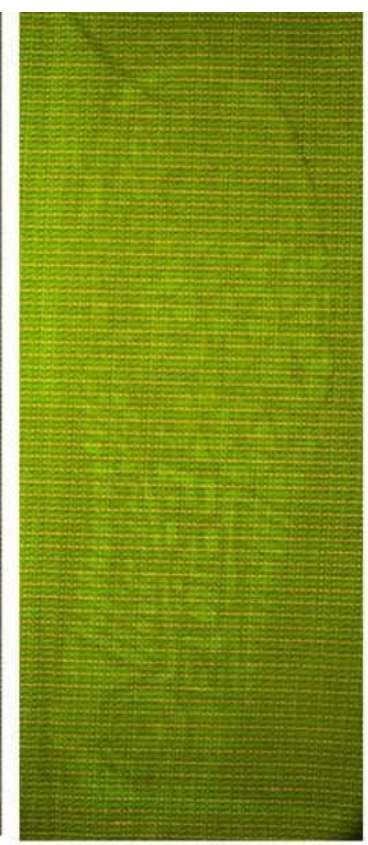

(b)

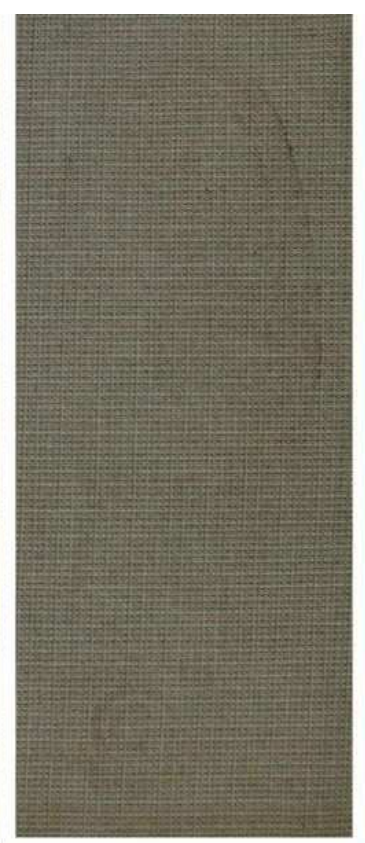

(c)

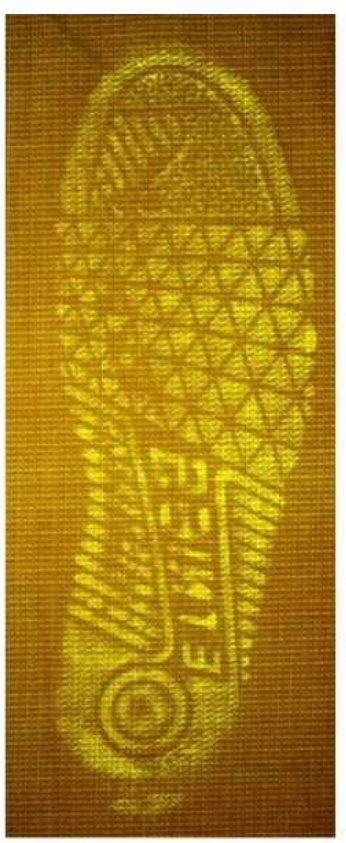

(d)

Figure 14 - Enhancement of a footwear impression in urine on patterned cotton: (a) urine impression after 1 week; (b) enhancement with fluorescence only using blue excitation filter [385-509nm]; (c) 1,2-IND visual enhancement; (d) 1,2-IND enhancement using a Quaser 40 green excitation source

\section{Sensitivity}

\section{Diminishing Series}

A diminishing series of footwear impressions in urine was prepared for the light coloured fabrics only: white cotton, white nylon/lycra and patterned cotton. Polyester was excluded because of the previously observed diffusion of the urine impression and dark fabrics were excluded as no enhancement (visual or fluorescence) was obtained. The marks were enhanced with DFO, DMAC and ninhydrin only as the best performing techniques. DFO enhancement outperformed both DMAC and ninhydrin enhancement on white cotton as illustrated in figures 15. Similar results were observed for patterned cotton and white nylon/lycra although background staining on nylon/lycra interfered with DMAC fluorescence. The enhancement of urine impressions using DFO proved to be the most 
sensitive, (figure 15(b)) although the fourth and fifth impressions were weak, however, neither impression was enhanced with ninhydrin or DMAC. General fluorescence examination only provided enhancement up to the second impression in the series.
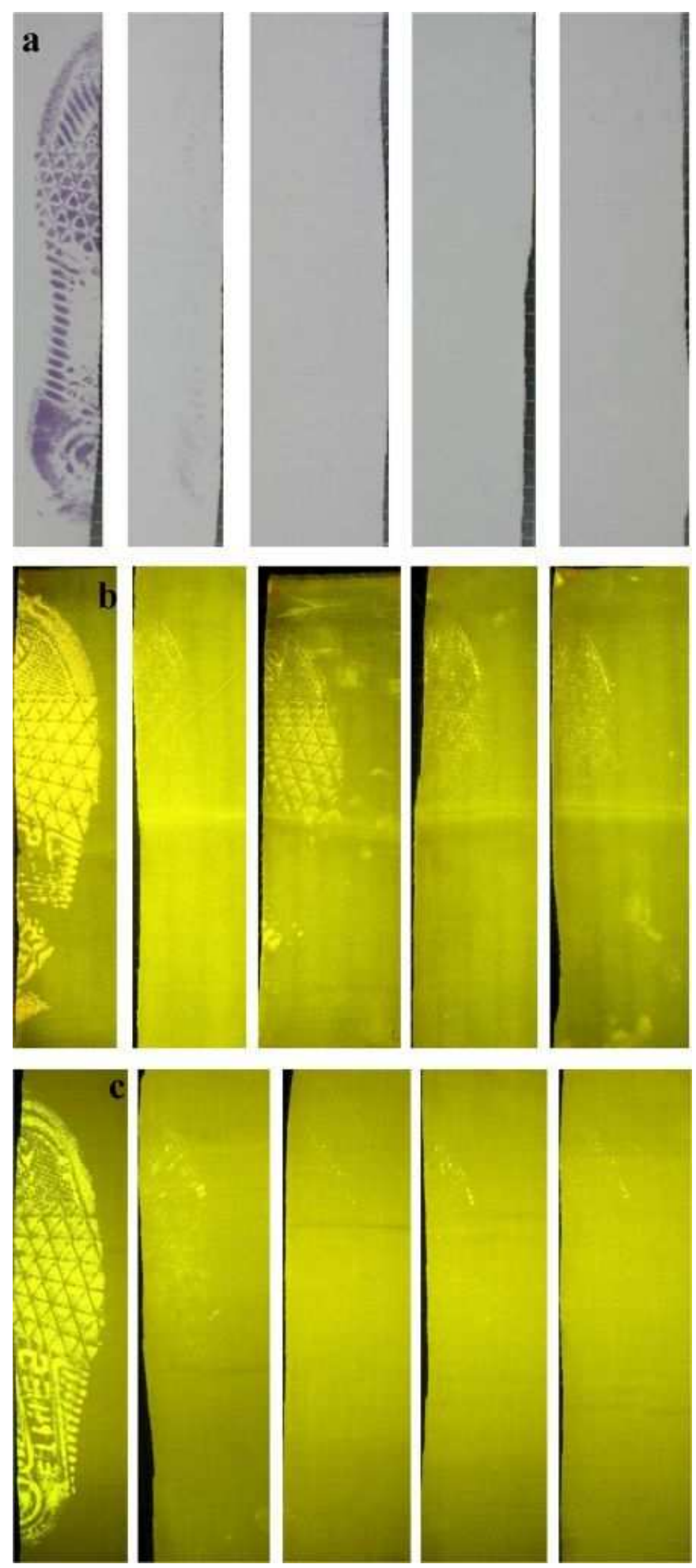

Figure 15 - Diminishing series (from left to right) of footwear impressions in urine on white cotton enhanced with (a) ninhydrin, (b) DFO fluorescence and (c) DMAC fluorescence 
The first urine impression on patterned cotton shows that DFO and DMAC (figure 16(b)) offer similar enhancement results, however, DFO outperformed DMAC as the urine impressions weakened. DMAC enhancement was superior to ninhydrin on white and patterned cotton when fluorescence was used, however, ninhydrin was superior to DMAC on white nylon/lycra as the extensive background staining hindered the enhancement using DMAC (figure 16(c)).

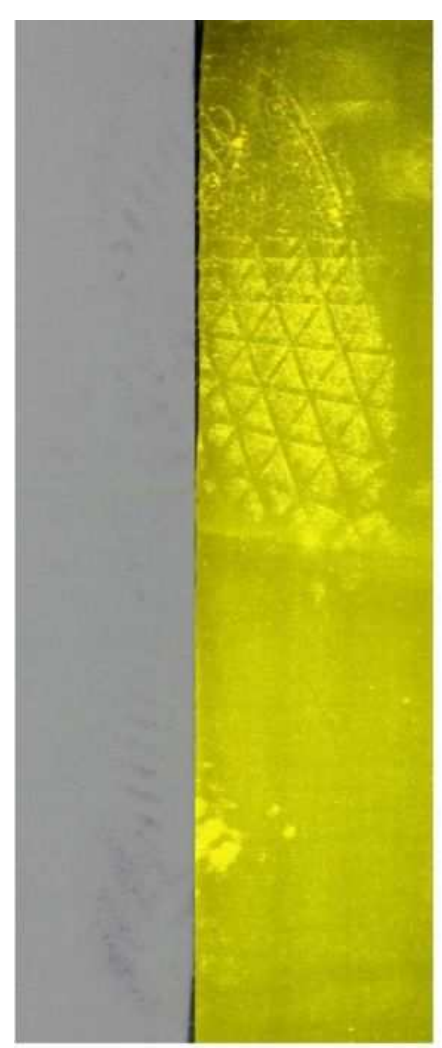

(a)

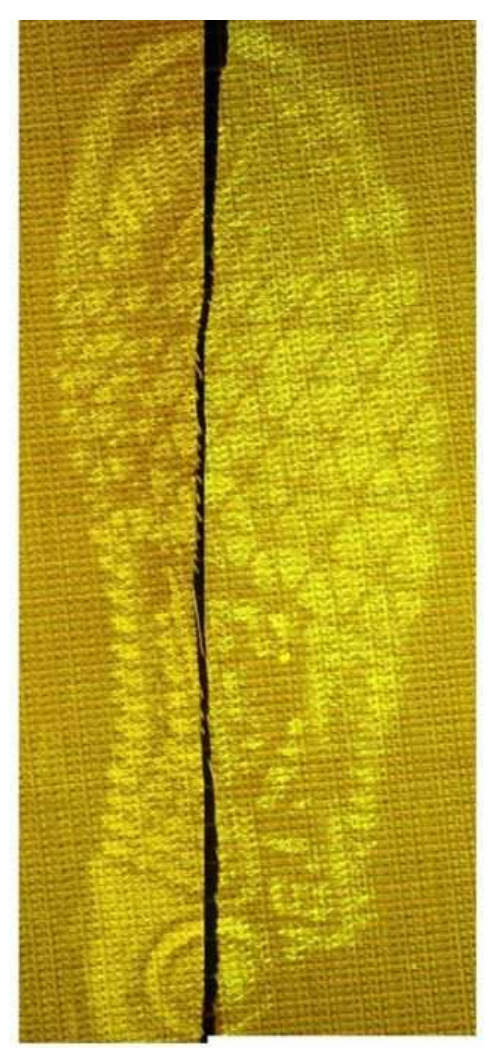

(b)

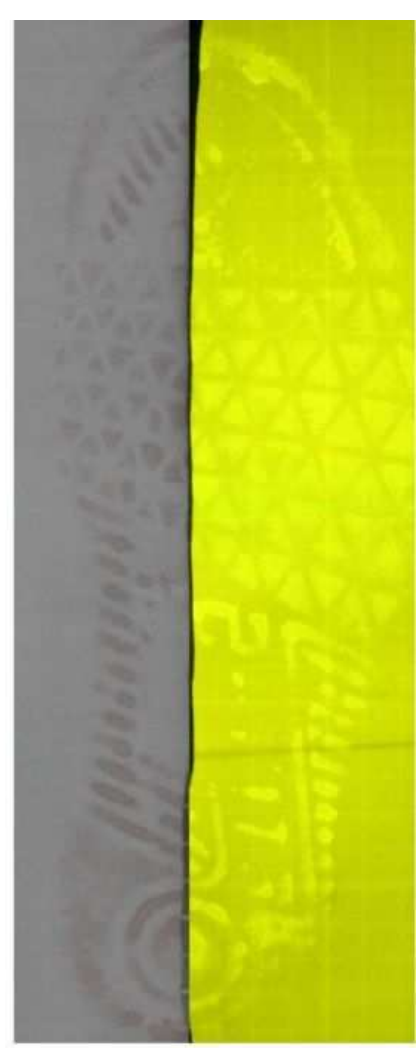

(c)

Figure 16 - Diminishing series of footwear impressions in urine (a) NIN-DFO on white cotton $2^{\text {nd }}$ impression; (b) DFO-DMAC on patterned cotton $1^{\text {st }}$ impression; (c) NIN-DMAC on white nylon/lycra $1^{\text {st }}$ impression

\section{Ageing Study and Sequential Treatment}

The ageing study and sequential treatment investigation were carried out together. Footwear impressions in urine were prepared as described previously and left to age for two months. Three repeat marks on white cotton, patterned cotton and white nylon/lycra respectively were treated with ninhydrin, DFO and DMAC. Sequential treatments considered were as follows: DFO-NIN, DFO-NIN-DMAC, NIN-DFO and DMAC-DFO-NIN. Sequential treatment of DFO and ninhydrin is well established for fingerprints where the use of ninhydrin after DFO 
can improve enhancement. In contrast little or no further development occurs if DFO is used after ninhydrin [7]. Consequently the sequence DMAC-NIN-DFO was not considered.

After ageing the urine impressions for two months, DFO provided excellent enhancement detail with a visual pink-magenta colour that was brighter than the one-week old impressions. DFO enhancement on patterned cotton could be observed readily as illustrated in figure 17 with no added advantage with fluorescence. Ninhydrin enhancement, by contrast, on the two month old impressions was weaker than one week old impressions. The impression could be slightly visualised on white cotton and nylon/lycra, however, the impression on the patterned cotton provided poor contrast as illustrated in figure 18. Similar to ninhydrin, enhancement of the two month old impressions using DMAC was poor except for white cotton, even when fluorescence was used (figure 19).

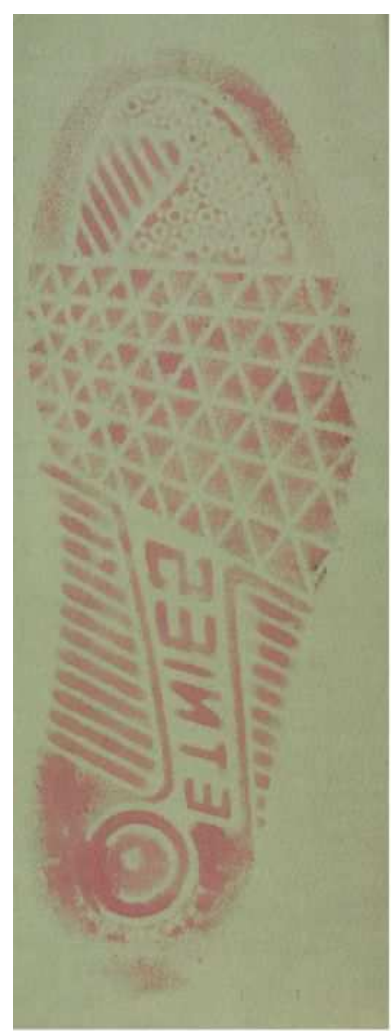

(a)

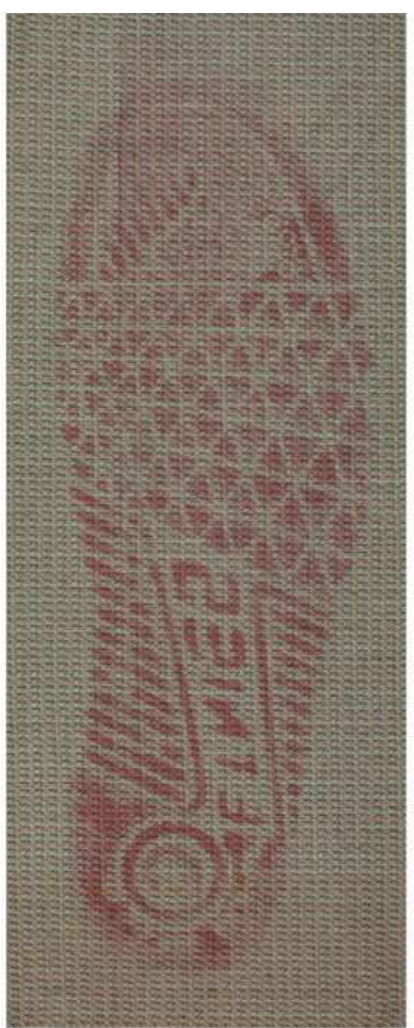

(b)

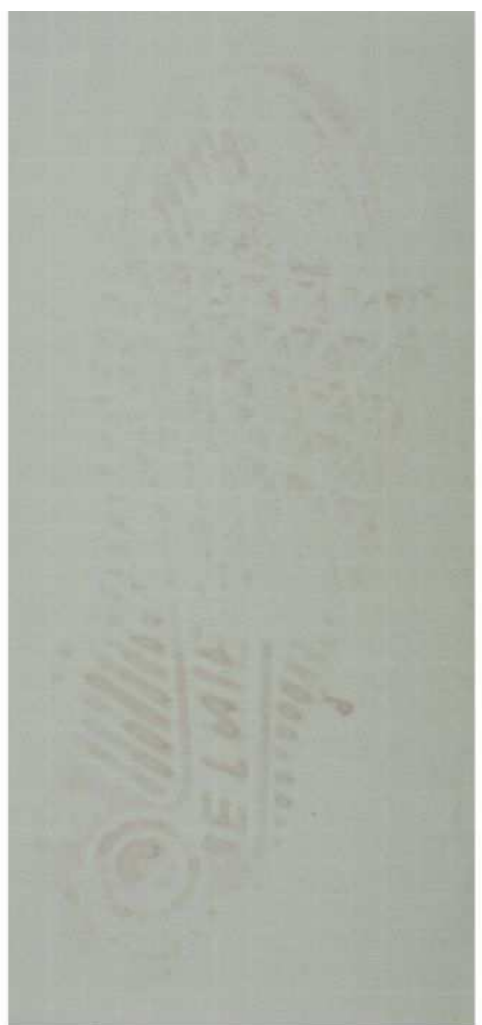

(c)

Figure 17 - Enhancement of two month old footwear impressions in urine with DFO under white light (a) white cotton; (b) patterned cotton; (c) white nylon/lycra 


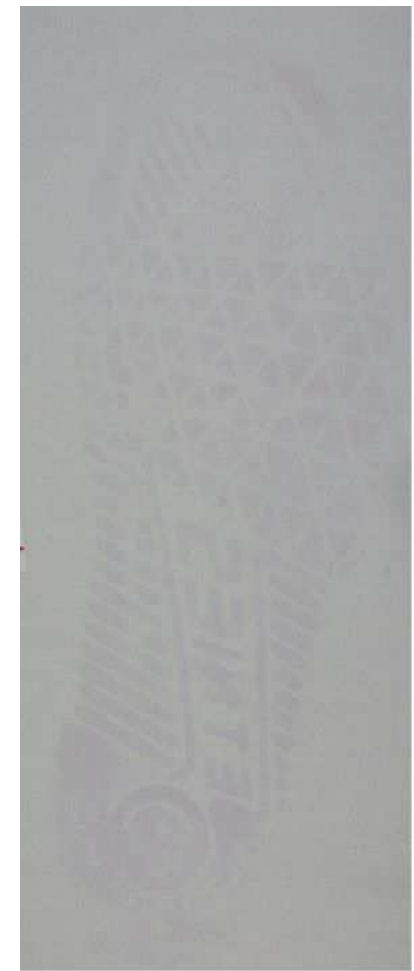

(a)

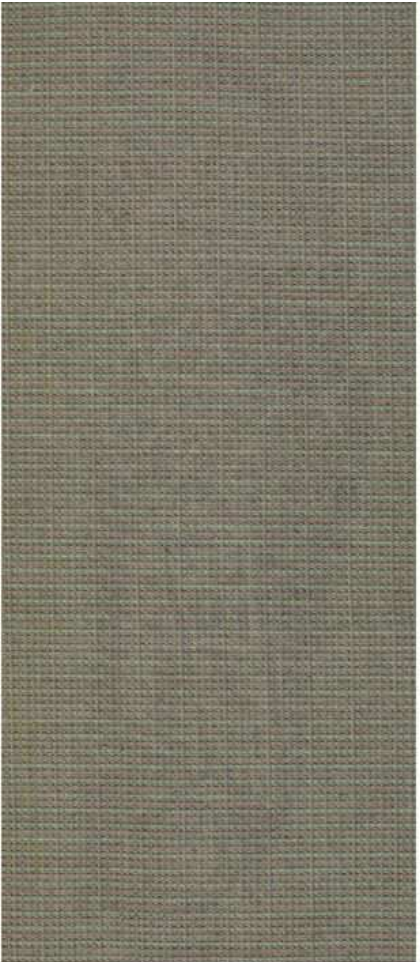

(b)

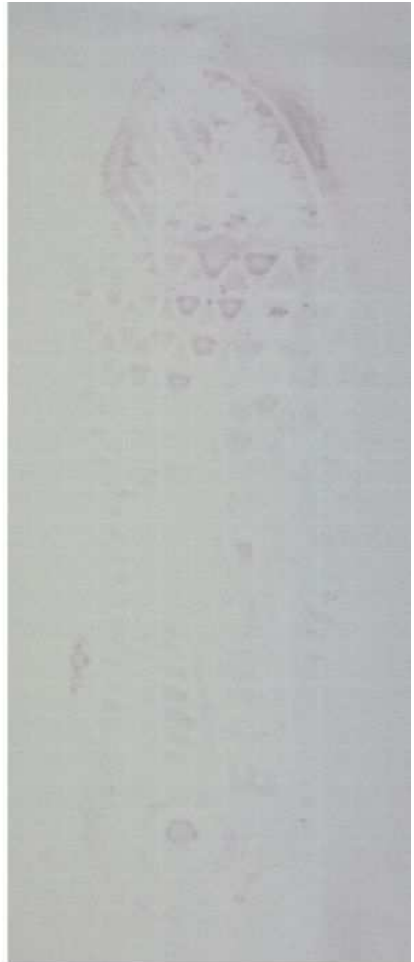

(c)

Figure 18 - Enhancement of two month old footwear impressions in urine with ninhydrin (a) white cotton; (b) patterned cotton; (c) white nylon/lycra

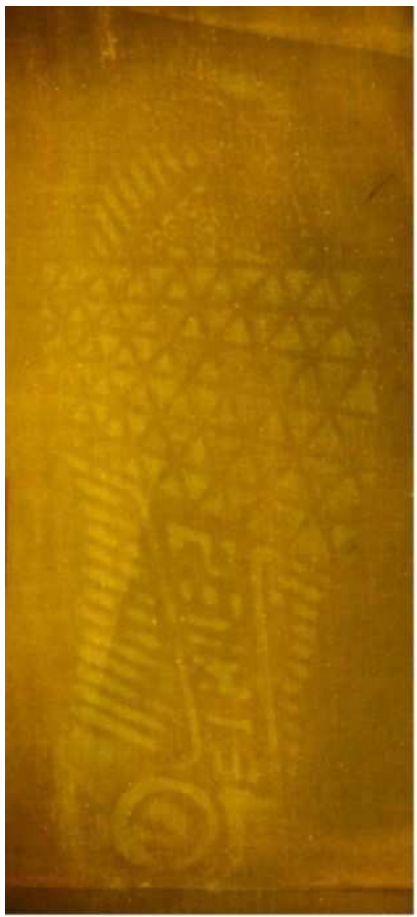

(a)

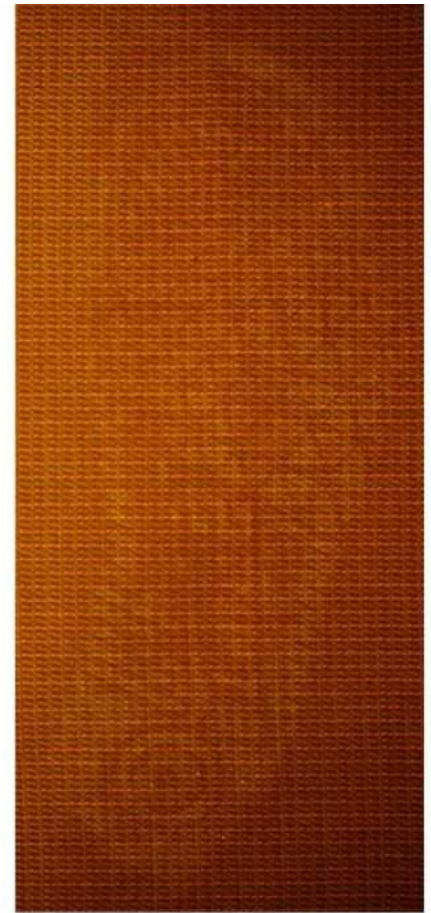

(b)

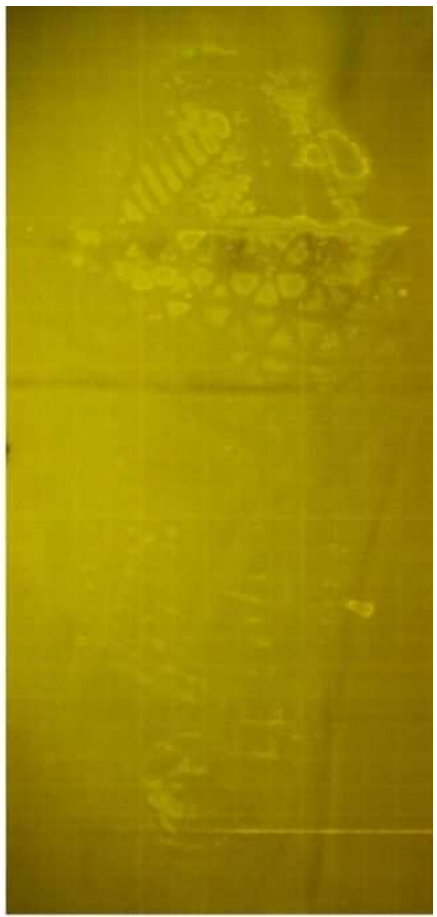

(c)

Figure 19 - Enhancement of two month old footwear impressions in urine with DMAC fluorescence (a) white cotton; (b) patterned cotton; (c) white nylon/lycra 
Of the sequential treatments examined, DMAC-DFO provided some improvement in the enhancement observed with marks on white and patterned cotton as illustrated in figure 20 . However, when DFO was used after DMAC on white nylon/lycra, background staining developed to mask the enhanced impression. In general, the use of DFO alone developed the best impressions across the fabrics examined rather than when used in a sequential treatment and this is in agreement with the work of Lee et al [12].

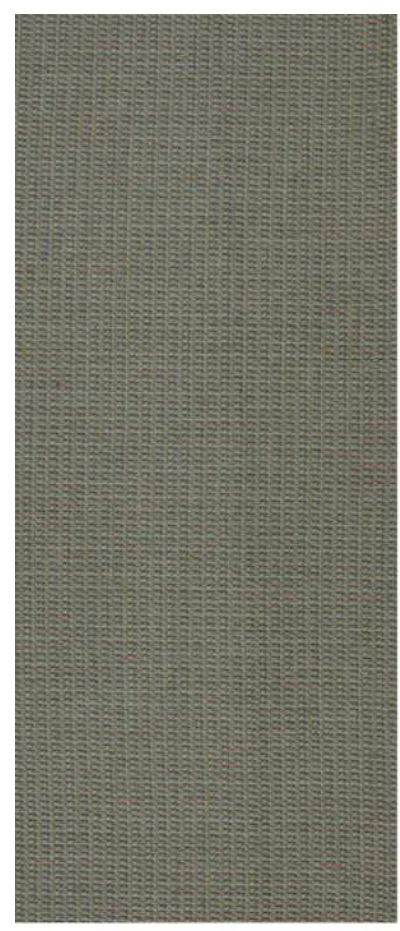

(a)

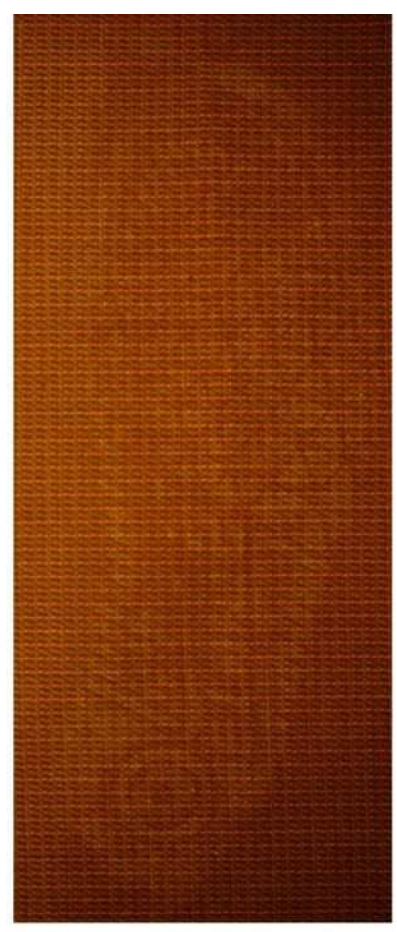

(b)

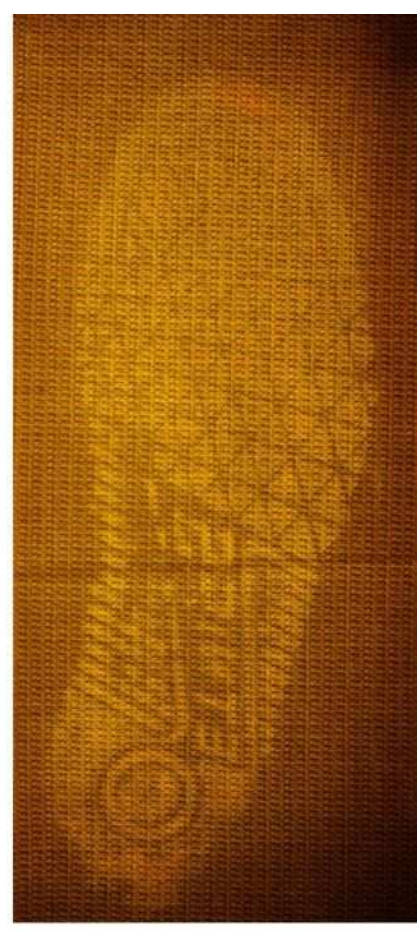

(c)

Figure 20 - Sequential enhancement of a footwear impression in urine on patterned cotton (a) 2 month old urine impression; (b) DMAC enhancement under green light; (c) DMAC-DFO enhancement using a Quaser 40 green excitation source

\section{Case Study}

A study to assess the potential enhancement of footwear impressions in urine in a realistic case scenario was also examined. The test area chosen was a male restroom within the student's union at the University on a busy evening. This area was being frequently used during the evening of the test. The researcher walked across the floor area and then stamped on a clean piece of white cotton. This was repeated to provide three test samples in total. The test fabric was collected, packaged in paper bags and stored for one week prior to analysis. After one week, a footwear impression in urine was weakly visible on the samples. Enhancement by DFO greatly improved the quality of the impression in all cases and is illustrated in figure 21. 


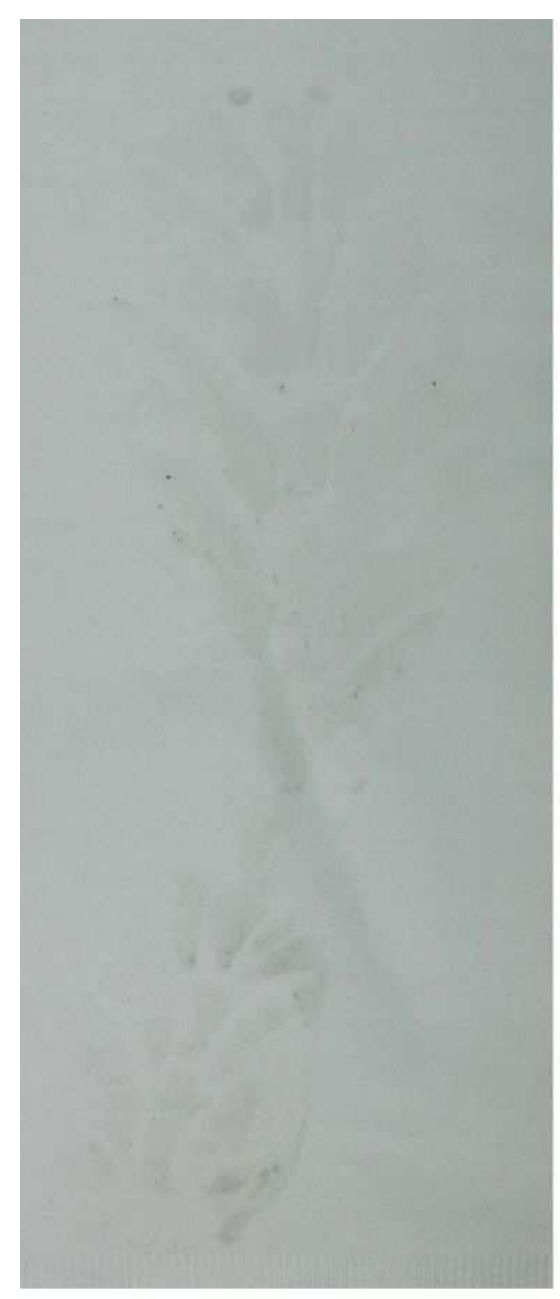

(a)

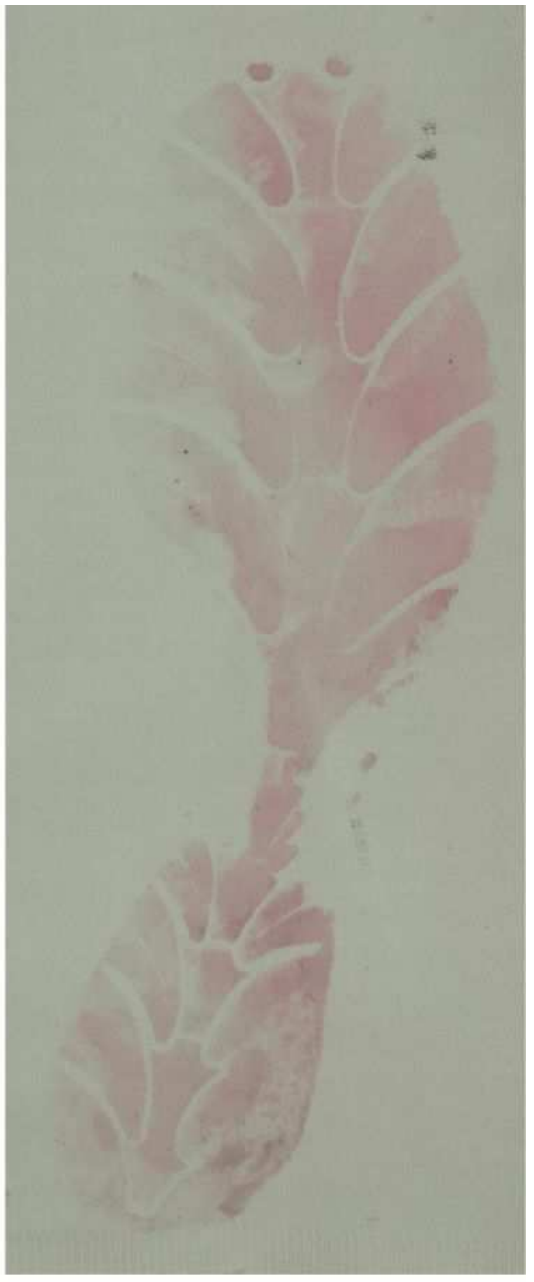

(b)

Figure 21 - Enhancement of one week old footwear impression in urine during a case scenario: (a) after one week; (b) DFO enhancement under white light 


\section{CONCLUSION}

This study has comprehensively explored the enhancement of impressions made in urine on various types of fabric. It has reasserted the fact that urine from different individuals can exhibit different fluorescent properties but that in general strong fluorescence is observed by using a violet/blue excitation source (350-469nm) and viewing with a yellow filter $(476 \mathrm{~nm})$.

It has been demonstrated that four reagents, 1,2-IND, ninhydrin, DMAC and DFO all provide some enhancement of the marks to varying degrees and in some cases even after a period of two months post deposition. Of these DFO provided the best enhancement overall with no tangible advantage observed when the reagents are used in sequence.

Enhancement was only possible on lighter coloured fabrics with the more porous fabrics (cotton and patterned cotton) providing the best results. It is suggested that the presence of dyestuffs or other chemical products may inhibit the fluorescence of urine and the fluorescence of the chemically enhanced urine stains.

DFO, ninhydrin and 1,2-IND are versatile chemical enhancement reagents as they will also enhance impressions in blood, as such their potential as general screening reagents for a second body fluid is most advantageous. Furthermore, it has been demonstrated that nondestructive lighting techniques can provide suitable means of enhancing marks in urine and that the use of alternative or oblique lighting should be performed first before any chemical treatment.

\section{ACKNOWLEDGEMENTS}

The authors would like to thank CAST, EPSRC and the University of Strathclyde for their continued financial support. This work is also partially funded by the Malta Government Scholarship Scheme. Special thanks to Andrew Gibson at CAST for his assistance in using alternative lighting, lasers and the spectrofluorophotometer. 


\section{REFERENCES}

1. R.E. Gaensslen, Sourcebook in Forensic Serology, Immunology and Biochemistry, U.S. Department of Justice, (1983)

2. K. Virkler, I.K. Lednev, Analysis of body fluids for forensic purposes: From laboratory testing to non-destructive rapid confirmatory identification at a crime scene, Forensic Science International, 188 (1-3) (2009) 1-17.

3. A. Greenfield, M.A. Sloan, Identification of Biological Fluids and Stains, in Forensic Science: an Introduction to Scientific and Investigative Techniques, James, S.H. and J.J. Nordby, Editors. 2003, CRC Press, Boca Raton: FL. p. 203-220.

4. H.C. Lee, R.E. Gaensslen, Advances in Fingerprint Technology, CRC Press LLC, (2001)

5. C. Champod, C.J. Lennard, P. Margot, S. Milutin, Fingerprints and Other Ridge Skin Impressions, CRC Boca Raton, (2004)

6. R.S. Ramotowski, Composition of Latent Print Residue, in Advances in Fingerprint Technology, Lee, H.C. and R.E. Gaensslen, Editors. 2001, CRC Press Boca Raton: Florida. p. 64-104.

7. V. Bowman, ed. Manual of Fingerprint Development Techniques. 2nd ed. 2005, Home Office Scientific Development Branch: Sandridge, UK.

8. V. Bowman, ed. Fingerprint Development Handbook. 2nd ed. 2005, Home Office Scientific Development Branch: Sandridge, UK.

9. D.F. Hewlett, V.G. Sears, S. Suzuki, Replacements for CFC113 in the Ninhydrin Process: Part 2, Journal of Forensic Identification, 47 (3) (1997) 300-331.

10. D.F. Hewlett, V.G. Sears, An Operational Trial of Two Non-ozone Depleting Ninhydrin Formulations for Latent Fingerprint Detection, Journal of Forensic Identification, 49 (4) (1999) 388-396.

11. G.C. Goode, J.R. Morris, Latent Fingerprints: A Review of Their Origin, Composition and Methods for Detection. 1983, Technical AWRE Report No. 022/83: Aldermaston, U.K.

12. J.L. Lee, S. Bleay, V.G. Sears, S. Mehmet, R. Croxton, Evaluation of the Dimethylaminocinnamaldeyhde Contact Transfer Process and its Application to Fingerprint Development on Thermal Papers, Journal of Forensic Identification, 59 (5) (2009) 545-568.

13. Y. Sasson, J. Almog, Chemical Reagents for the Development of Latent Fingerprints 1: Scope and Limitations of the Reagent 4-Dimethylaminocinnamaldehyde, Journal of Forensic Science, 23 (4) (1978) 852-855.

14. C. Champod, C.J. Lennard, P. Margot, M. Stoilovic, Fingerprints and Other Ridge Skin Impressions, CRC Boca Raton, (2004)

15. J. Flynn, M. Stoilovic, C. Lennard, Detection and Enhancement of Latent Fingerprints on Polymer Banknotes: A Preliminary Study, Journal of Forensic Identification, 49 (6) (1999) 594-613.

16. J.S. Brennan, S.K. Bramble, S. Crabtree, G. Wright, Fuming of Latent Fingerprints Using Dimethylaminocinnamaldehyde, Journal of Forensic Identification, 45 (4) (1995) 373-380.

17. J.S. Brennan. The Development of Fingerprints by Fuming with Dimethylaminocinnamaldehyde (DMAC). in Proceedings of the International Symposium on Fingerprint Detection and Identification, (1996) Ne'urim, Israel: Israel National Police.

18. R.S. Ramotowski. Fluorescence Visualisation of Latent Fingerprints on Paper using $\mathrm{p}=$ Dimethylaminocinnamaldehyde (PDMAC). in Proceedings of the International Symposium on Fingerprint Detection and Identification, (1996) Ne'urim, Israel: Israel National Police.

19. K.J. Farrugia, N. NicDaéid, K.A. Savage, H.L. Bandey, Chemical enhancement of footwear impressions in blood deposited on fabric - Evaluating the use of alginate casting materials followed by chemical enhancement, Science \& Justice, 50 (4) (2010) 200-204.

20. K.J. Farrugia, K.A. Savage, H.L. Bandey, N. Nic Daeid (2011) Chemical Enhancement of Footwear Impressions in Blood on Fabric - Part 1: Protein Stains, Science and Justice In Print, DOI: 10.1016/j.scijus.2010.11.001. 
21. K.J. Farrugia, K.A. Savage, H.L. Bandey, T. Ciuksza, N. Nic Daéid (2011) Chemical Enhancement of Footwear Impressions in Blood on Fabric - Part 2: Peroxidase reagents, Science \& Justice In Print, DOI: 10.1016/j.scijus.2010.11.002.

22. V.G. Sears, R. Batham, S. Bleay, The Effectiveness of 1,2-Indanedione-Zinc Formulations and Comparison with HFE-Based 1,8-diazafluoren-9-one for Fingerprint Development, Journal of Forensic Identification, 59 (6) (2009) 654-678.

23. R. Li, Forensic Biology: identification and analysis of biological evidence, Boca Raton: CRC Press, (2008)

24. S. Hardwick, T. Kent, V.G. Sears, Fingerprint Detection by Fluorescence Examination: A Guide to Operational Implementation. 1990, Home Office Police Scientific Development Branch 3/90: London.

25. V.G. Sears, C.P.G. Butcher, L.A. Fitzgerald, Enhancement of Fingerprints in Blood - Part 3: Reactive Techniques, Acid Yellow 7, and Process Sequences, Journal of Forensic Identification, 55 (6) (2005) 741-763.

26. J. Kušnír, K. Dubayová, L. Lešková, M. Lajtár, Concentration Matrices-Solutions for Fluorescence Definition of Urine, Analytical Letters, 38 (10) (2005) 1559 - 1567.

27. M.J.P. Leiner, M.R. Hubmann, O.S. Wolfbeis, The Total Fluorescence of Human Urine, Analytica Chimica Acta, 198 (1987) 13-23.

28. P.M. Sandeepa, K.P. Unnikrshnanb, S. Vemulpadc, E.M. Goldysa, Factors influencing the UV autofluorescence of human urine, in International Conference on Optics and Photonics. 2009, 30th October - 1st November: Chandigarh, India.

29. M. Bannister, The use of ultra-violet imaging in the detection of forensic evidence, in Department of Natural Sciences. 2009, University of Bath: Bath.

30. L.G. Rasmussen, F. Savorani, T.M. Larsen, L.O. Dragsted, A. Astrup, S.B. Engelsen, Standardization of factors that influence human urine metabolomics, Metabolomics, 7 (2011) 71-83.

31. M. Agarwal, R. Herlihy, A. Reitnauer, A comparative study of the development of blood impressions on dark-coloured substrates using phloxine B and and acid yellow 7, Fingerprint Whorld, 36 (140) (2010) 98-111.

32. R.K. Morgan-Smith, D.A. Elliot, H. Adam, Enhancement of Aged Shoeprints in Blood, Journal of Forensic Identification, 59 (1) (2009) 45-50.

33. M. Stoilovic, Detection of semen and blood stains using polilight as a light source, Forensic Science International, 51 (2) (1991) 289-296.

34. M. Stoilovic, Improved method for DFO development of latent fingerprints, Forensic Science International, 60 (3) (1993) 141-153.

35. J. Almog, E. Springer, S. Wiesner, A. Frank, O. Khodzhaev, R. Lidor, E. Bahar, H. Varkony, S. Dayan, S. Rozen, Latent Fingerprint Visualization by 1,2-Indanedione and Related Compounds: Preliminary Results, Journal of Forensic Science, 44 (1) (1999) 114-118.

36. C. Roux, N. Jones, C. Lennard, M. Stoilovic, Evaluation of 1,2-Indanedione and 5,6Dimethoxy-1,2-Indanedione for the Detection of Latent Fingerprints on Porous Surfaces, Journal of Forensic Science, 45 (4) (2000) 761-769.

37. S. Wiesner, E. Springer, Y. Sasson, J. Almog, Chemical Development of Latent Fingerprints: 1,2-Indanedione has Come of Age, Journal of Forensic Science, 46 (5) (2001) 1082-1084.

38. S. Merrick, S.J. Gardner, V.G. Sears, D.F. Hewlett, An operational trial of ozone-friendly DFO and 1,2-indandione formulations for latent fingerprint detection, Journal of Forensic Identification, 52 (5) (2002) 595-605.

39. S.J. Gardner, D.F. Hewlett, Optimization and Initial Evaluation of 1,2-Indandione as a Reagent for Fingerprint Detection, Journal Of Forensic Science, 48 (6) (2003) 1-5.

40. D. Wilkinson, The Results from a Canadian National Field Trial Comparing Two Formulations of 1,8-Diazafluoren-9-one (DFO) with 1,2-Indanedione, Identification Canada, 26 (2) (2003) 8-18. 
41. C. Wallace-Kunkel, C. Roux, C. Lennard, M. Stoilovic, The Detection and Enhancement of Latent Fingermarks on Porous Surfaces - A Survey, Journal of Forensic Identification, 56 (4) (2004) 687-705.

42. D.E. Bicknell, R.S. Ramotowski, Use of an Optimized 1,2-Indanedione Process for the Development of Latent Prints*, Journal of Forensic Sciences, 53 (5) (2008) 1108-1116.

43. J. Chan, A. Brust, X. Spindler, R. Shimmon, P. Maynard, C. Lennard, M. Stoilovic, C. Roux, Evaluation of DFO and 1,2-Indanedione-Zinc Formulations Under Two Different Australian Conditions, in 5th European Academy of Forensic Science Conference. 2009: Glasgow, Scotland, UK. 